\title{
Yield Characteristics Strengthening and Yield Strength Anti-Dispersion Identification Based on Bending Deformation
}

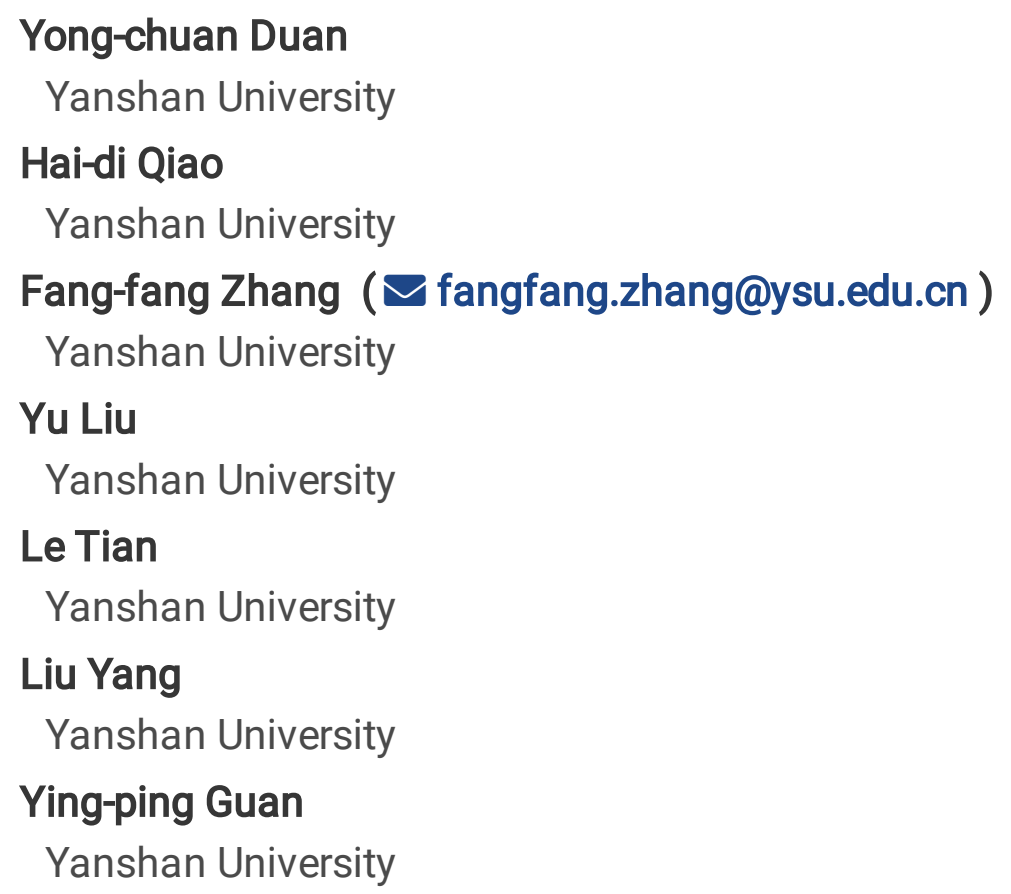

\section{Original Article}

Keywords: Bending deformation, Yield Strength, Yield characteristics strengthening, Window vector method, Identification

Posted Date: October 9th, 2020

DOI: https://doi.org/10.21203/rs.3.rs-87235/v1

License: (a) (1) This work is licensed under a Creative Commons Attribution 4.0 International License. Read Full License 


\section{Title page}

\section{Yield characteristics Strengthening and Yield Strength Anti-dispersion Identification Based on Bending Deformation}

Yong-chuan Duan, born in 1983, is currently a PhD at Key Laboratory of Advanced Forming \& Stamping Technology and Science,Yanshan University, China. He received his $\mathrm{PhD}$ degree from Yanshan University, China, in 2014. His research interests include metal material damage and fatigue.

Tel: +86-13253118982; E-mail: yonghcuan.duan @ysu.edu.cn

Hai-di Qiao, born in 1994, is currently a master candidate at Key Laboratory of Advanced Forming \& Stamping Technology and Science,Yanshan University, China.

E-mail:qiao741380857@163.com

Fang-fang Zhang, born in 1984, is currently a PhD at Key Laboratory of Advanced Forming \& Stamping Technology and Science, Yanshan University, China. She received her PhD degree from Yanshan University, China, in 2014. Her research interests include damage and fatigue of braided composites.

Tel: +86-13223387868; E-mail: fangfang.zhang @ysu.edu.cn

Yu Liu, born in 1998, is currently a master candidate at Key Laboratory of Advanced Forming \& Stamping Technology and Science,Yanshan University, China.

E-mail: 15538204689@163.com

Le Tian, born in 1993, is currently a master candidate at Key Laboratory of Advanced Forming \& Stamping Technology and Science,Yanshan University, China.

E-mail: wolfganglele@gmail.com

Liu Yang, born in 1988, is currently a PhD at Key Laboratory of Advanced Forming \& Stamping Technology and Science, Yanshan University, China.

E-mail: yangliu@ysu.edu.com

Ying-ping Guan, born in 1963, is currently a professor at Yanshan University, China. He received his PhD degree from Yanshan Universtiy, China, in 2000. His research interests include metal material damage and fatigue.

E-mail: gyp@ysu.edu.cn

Corresponding author: Fang-fang Zhang E-mail: fangfang.zhang@ysu.edu.cn 


\title{
Yield characteristics Strengthening and Yield Strength Anti-dispersion Identification Based on Bending Deformation
}

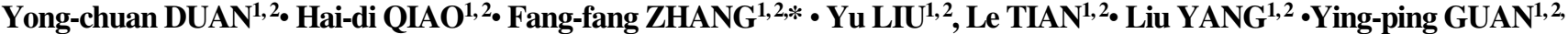

Received June xx, 201x; revised February xx, 201x; accepted March xx, 201x

(C) Chinese Mechanical Engineering Society and Springer-Verlag Berlin Heidelberg 2017

\begin{abstract}
The online derivation of material yield is important for consistency control of product quality. Compare with other deformation, bending deformation is more suitable for online identification. The transition portion of bending force stroke curve is related to the yield strength of material, but for a wide set of materials with different thickness and properties, its longer transition curve shows higher identification scattering. In this paper, the yield characteristics strengthening method and the new anti-dispersion identification method are studied to reduce the scattering. It is found that the yield characteristics are comprehensively affected by several factors. The higher yield strength, together with thinner thickness, can weaken the yield characteristics. The thicker material with wider die span can strengthen the yield characteristics. Window vector method (WV) and standardized fitting residual method (SFR) are proposed. Through the numerical study found that the yield load obtained by WV method shows a most accurate correlation with yield strength. A novel piecewise correlation equation is proposed and added a thickness variable to eliminate partial dispersion from varied thickness. Furthermore, this paper uses the experimental data to extract the generalization error of new correlation model fitted by yield loads from WV method, maximum error is below $12 \%$. This method can improve the accuracy and efficiency of online ranking materials.
\end{abstract}

Keywords: Bending deformation • Yield Strength • Yield characteristics strengthening $\bullet$ Window vector method $\bullet$ Identification

$\triangle \quad$ Fang-fang Zhang

fangfang.zhang @ysu.edu.cn

1 Key Laboratory of Advanced Forming \& Stamping Technology and Science, Ministry of Education of China, Yanshan University,Qinhuangdao 066004, Hebei, China

2 College of Mechanical Engineering, Yanshan University, Qinhuangdao 066004, Hebei, China

\section{Introduction}

Sheet metal exhibits complex behaviors in the process of deformation, such as deformation resistance, bending spring-back [1-3], fracture [3-7], and failure [8-11]. The deformation can be better controlled by precisely understanding the deformation behavior of material $[12,13]$. Therefore, it is very importance to accurately identify mechanical parameters for each sheet metal in production line[14, 15]. In addition, the sheet metal has yield parameter fluctuation caused by different batches [16-18]. If the fluctuation is accurately identified online, the feed forward and feedback methods can be applied to control the consistency of the forming process, such as free bending, stretch bending, drawing, etc[19].

The yield behavior of the sheet metal is the result of transition from elastic deformation to plastic deformation. At present, many scholars use the uniaxial tensile test to identify the yield parameters [20,21], but the elastic displacement of the uniaxial tensile test is short. Naturally, relative errors of yield parameters are sensitive to the interference caused by relative sliding between clamp and specimen. This method is almost impossible to achieve online monitoring with so complex test setup and dog bone shape specimen. When the amount of test material is limited, some scholars use small punch test (SPT) to identify yield strength and tensile strength [22-25]. Chica et al. have studied the elastic modulus based on SPT [26]. Chica et al. have identified and studied the yield parameters of the material based on SPT [27]. Prieletal analyzed material strength based on SPT, and material strength identification method was established [28].

In the early stage of SPT, the axisymmetric elastic bending is dominated [29]. Deformation continues, the bulging deformation is gradually dominated [30]. There is a transition portion of SPT curve, which is related to yield behavior, and it 
can be used to identify the yield strength. However, the deformation mode of SPT changes at different thickness of sheet metal [31]. When the material is thin, the plate bending is weakened, and the membrane stretching arrives early. So, the transition portion is weakened, or even disappeared. Many scholars use the correlation model as follow [32]

$$
\sigma_{y s}=\alpha_{1} \frac{P_{y}}{t^{2}}+\alpha_{2}
$$

However, the slope factor is not a dimensionless coefficient with different thicknesses. In addition, the absolute deformation of SPT is small, so it requires high accuracy equipment [33]. From above analysis, a more robust and anti-dispersion approach is needed for accurate online identification for yield strength. A better solution is to choose new deformation other than SPT to reduce the dispersion for online identification.

The deformation mechanism of free bending is similar to initial stage of SPT [34], and some scholars have studied bending process [35-38]. Wang et al. have used bending force-stroke curve to learn the springback parameters [39]. Imai et al. have applied the bending force-stroke curve to identify work hardening coefficient and exponent [40]. In previous literatures, authors do not use bending deformation to study the identification of yield strength. Compared with the SPT, force-stroke curve during yield deformation is longer, which enlarges the window for yield identification and reduces the sensitivity of identification error to measurement error, but longer transition curve during yield deformation increases the dispersion of identification.

In this paper, firstly, the influence of the parameters of the testing device on the transition curve is studied, the parameter combination and its influence mechanism of strengthening yield characteristics are determined. Secondly, the transition curve from the bending test is related to the yield parameter, but there is no direct corresponding relationship, so it needs to be transformed indirectly by mathematical method. two new identification methods are proposed. Finally, anti-dispersion identification methods are used to test a set of hypothetical materials, a new correlation model added independent thickness variable is fitted by identified yield loads. The prediction results show that the new correlation model fitted by yield loads from WV method can not only resist the dispersion, but also be robust and consistent in a wide set of materials with different thickness and properties.

\section{Test device and finite element model}

In the air bending test, the sheet metal is placed on two rollers of the die. The punch moves downward to complete the test.
The test device is shown in Figure 1. $r_{\mathrm{p}}$ is the punch radius, $D_{\mathrm{d}}$ is the roller diameter of die, $2 w$ is the die span, $t$ is thickness of sheet. The force stroke curve extracted from the bending test can be affected by above four parameters. When one of these four parameters is changed, and then the shape of the whole force stroke curve will be affected. The following section focuses on that how is the curve characteristics affected by these four parameters, and then the better parameter combination can be determined.

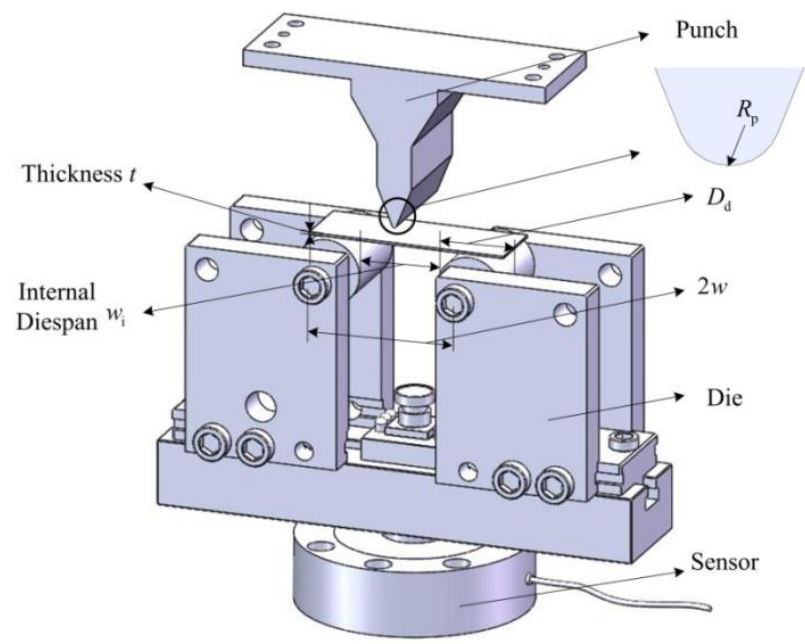

Figure 1.Bending test device.

\subsection{Establishment of the finite element model}

In order to analyze the influence of these parameters on the force stroke curve, the finite element model is used to analyze influence law. In ABAQ US, the implicit algorithm is applied. The established model is shown in Figure 2. Referring to the ASM standard, when the ratio of the width to thickness is greater than 8 , the strain in width can be assumed to be zero. The plane strain condition is satisfied. If less, stress in width can be assumed to be zero. The plane stress condition is satisfied. In this paper, the width of the specimen is $35 \mathrm{~mm}$, the length is $80 \mathrm{~mm}$, and thickness is depended on need. The punch and the die are defined as the analytical rigid body, and the four-node plane strain element CPS4 is selected to mesh the sheet. The friction coefficient of contact surfaces is set as 0.05 . In order to improve the stability and convergence of the model, the reference point of punch is set as a fixed boundary condition, and the corresponding bending stroke is applied to the reference point of die. 


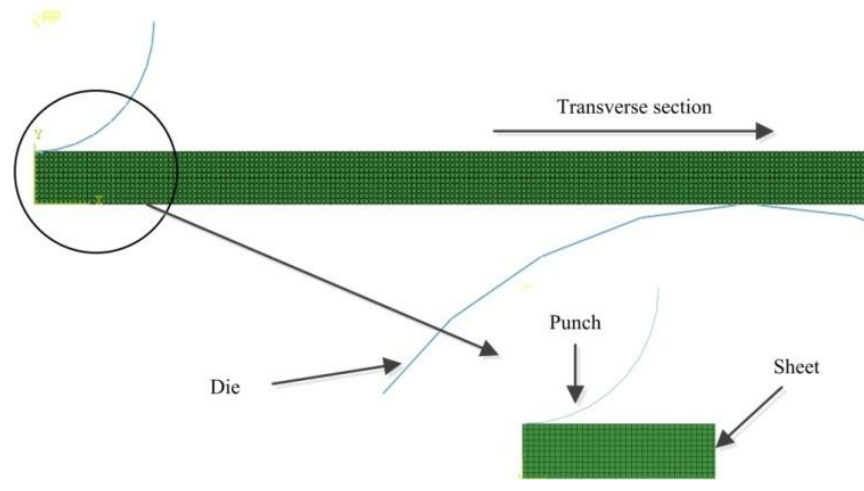

Figure 2. Finite element model of bending test.

\subsection{Stress-strain relationship}

The Ramberg-Osgood model is used to describe the hardening law of materials, where formula 3 is calculated for the hardening index. By setting the corresponding yield parameter and elastic modulus, strain can be calculated as follows:

$$
\begin{aligned}
& \varepsilon=\frac{\sigma}{E}+\varepsilon_{\text {offset }}\left(\frac{\sigma}{\sigma_{y}}\right)^{n} \\
& n=\frac{\ln \left(\frac{\varepsilon_{m}-\sigma_{m} / E}{\varepsilon_{\text {offset }}}\right)}{\ln \left(\frac{\sigma_{m}}{\sigma_{y}}\right)}
\end{aligned}
$$

Here $\varepsilon_{\text {offset }}$ is the offset strain, $\mathrm{n}$ is the hardening index, and $\sigma_{y}$ is the yield strength of sheet metal. E stands for the elastic modulus. In order to analyze the influence of different material parameters on the force stroke curve, the materials with high and low yield strength are selected for subsequent analysis. The elastic modulus of the two materials is $210 \mathrm{GPa}$, poisson's ratio is $0.3, n$ is 6.95 , and $\varepsilon_{\text {offset }}$ remains unchanged at 0.002 . Their yield strength is $100 \mathrm{MPa}$ and $1400 \mathrm{MPa}$, they are marked as $M Y H$ and $M Y L$, respectively. These two hypothetical materials are applied to analyze the shape changes of the force stroke curve.

\section{3. yield characteristics and Identification algorithms}

\subsection{Influence on yield characteristics}

Firstly, the influence of different spans and different sheet thicknesses on the shape of the force stroke curve is analyzed, and the punch radius of $5 \mathrm{~mm}$ and die radius of $10 \mathrm{~mm}$ are used to perform bending experiments. The die span is varied from
$20 \mathrm{~mm}$ to $50 \mathrm{~mm}$. The bending force stroke curves of the $M Y L$ material with $1 \mathrm{~mm}$ thickness under different spans are shown in Figure $3 \mathrm{a}$ ), the bending force stroke curves of the $M Y H$ material with $1 \mathrm{~mm}$ thickness are illustrated in the Figure $3 \mathrm{~b}$ ), and the bending force stroke curves of the $M Y L$ material with $2.35 \mathrm{~mm}$ thickness are demonstrated in the Figure $3 \mathrm{c}$ ). The bending force stroke curves of the $M Y H$ material with $2.35 \mathrm{~mm}$ thickness are explained in Figure $3 \mathrm{~d}$ ).

As can be seen from the curves in Figure 3 a), with the die span increasing, the bending load decreases gradually, because bending moment decreases as bending arm increasing. As the die span increases, the required load goes down naturally. Near stroke of $1.5 \mathrm{~mm}$, there is a transition curve in each transition zone, one of the curves marks the elastic zone, transition zone and plastic zone, which are shown in figure 3 a). Along with the increase of bending load, the transition curve follows. The die span decreases, by contrary, the transition curve rises. There is a peak point in each curve. With the decrease of the span, the load of peak point remains rising, but the peak point of the corresponding bending stroke under different spans has little change.

With the increase of the die span, the gap between the transition zone and the peak point is gradually widening. As the gap is increasing, the bending load changes slowly with the stroke, so it is conducive to algorithm identification. It can be seen from Figure $3 \mathrm{~b}$ ) that the overall curve shape of the $M Y H$ material is similar to that of the $M Y L$ material. As the die span increases, the yield stroke corresponding to transition curve follows. At the same time, the increase of the die span witness gradually rises in the stroke corresponding to the peak load on the curve. It can be seen from Figure $3 \mathrm{~b}$ ) that the overall shape of the $M Y H$ material at different spans is similar to that of the MYL material. when the die span is reduced, the overall curve shape of the high yield material is more protruding than that of the low yield material, and the transition zone is closer to the peak point. When the curve is fitted with a straight line and the remaining error is larger, it is unfavorable to the identification algorithm.

With the die span increases, the force stroke curve in elastic zone present slightly nonlinearity. The nonlinearity is unsuitable for some identification algorithms, and the applicability of different algorithms will be compared in the following. It can be seen from Figure $3 \mathrm{c}$ ) that when the thickness of sheet increases under the same yield condition, the bending force stroke curve goes up as a whole. Even under the different spans, the relative interval between the curves remains the same. Compared with Figure 3 b) and Figure 3 d), it can be notified that the increase of thickness is followed by the decrease in the curvature of curve near transition zone, which is of great importance to algorithm identification. Meanwhile, the non-linearity of the force stroke 
curve in the elastic zone goes down, which is beneficial for the identification.

Based on the above analysis, the rise of the thickness can slightly reduce the non-linearity of the force stroke curve in the elastic zone. In accordance with permitted length of the test sample, the large die span can be selected for the thin sheet with high yield strength while the small die span can be implemented on the thick sheet with low yield strength.
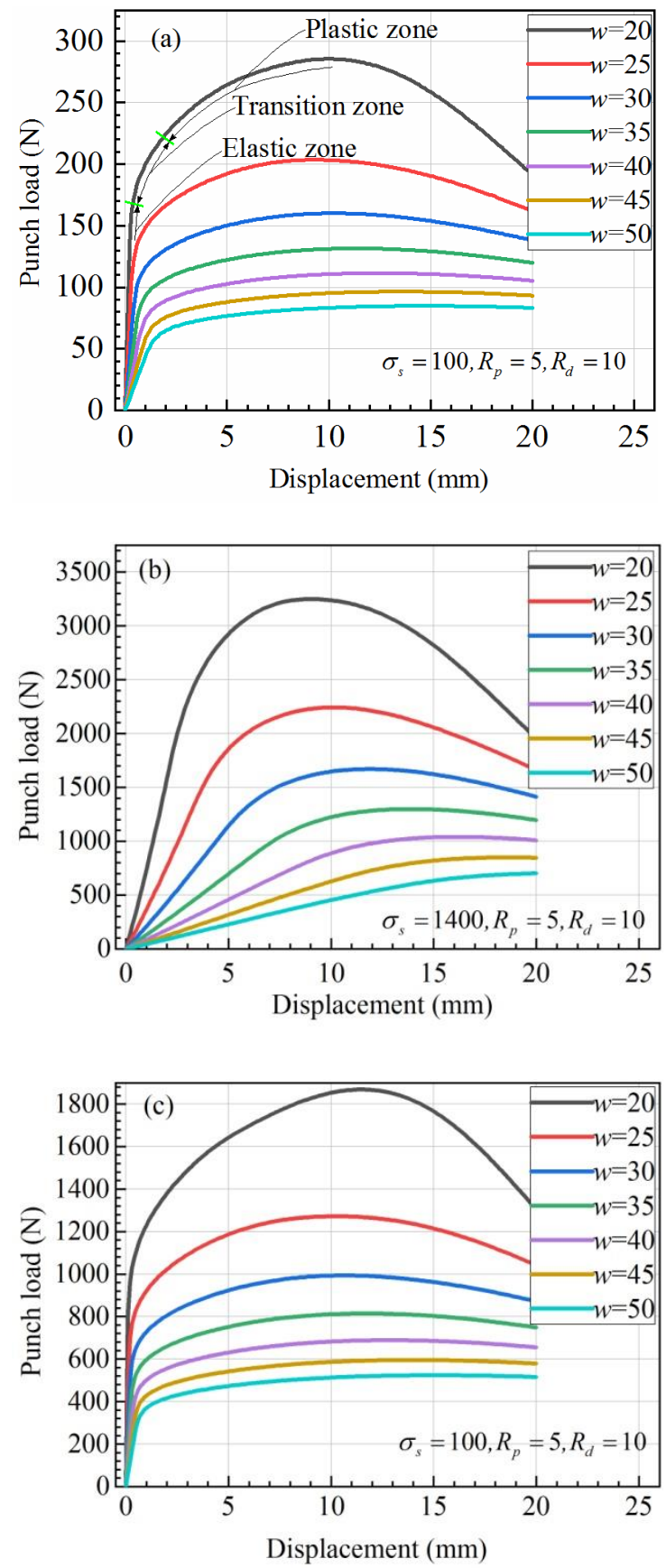

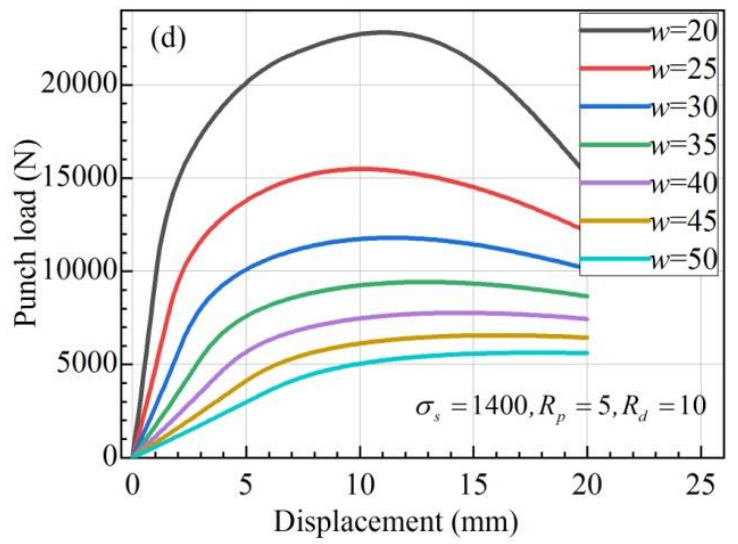

Figure 3.Curves of bending force travel under different die spans: a) MYL 1mm, b) $M Y H 1 \mathrm{~mm}$, c) $M Y L 2.35 \mathrm{~mm}$, d) $M Y H 2.35 \mathrm{~mm}$

To analyze the influence of different die radii on the bending curve, several curves have been listed below. The bending force stroke curve of a MYL material with $1 \mathrm{~mm}$ thickness is presented in Figure 4a), and the bending force stroke curve of a MYH material with $1 \mathrm{~mm}$ thickness is shown in Figure $4 \mathrm{~b}$ ). The bending force stroke curve of MYL material with $2.35 \mathrm{~mm}$ thickness is illustrated in Figure $4 \mathrm{c}$ ). The bending force travel curve of a $M Y H$ material with $2.35 \mathrm{~mm}$ thickness is explained in Figure $4 \mathrm{~d}$ ). Three groups of die radii are selected for the research, which are $10 \mathrm{~mm}, 20 \mathrm{~mm}$, and $30 \mathrm{~mm}$, respectively. Combined with the above analysis results, the large span is beneficial for the identification method. In this paper, the die span of $30 \mathrm{~mm}, 40 \mathrm{~mm}, 50 \mathrm{~mm}$ and three groups of die radii are selected for the analysis.

It can be concluded from Figure 4 a) that when the span remains the same, large die radius raises the bending force through yield transition zone. At this zone, the curvature change of force curve is small, and the linear fitting method is beneficial for improving the correlation. However, it has little effect on the curve near transition zone.

Figure 4 b) has shown that under the same span, different die radii have influences on the force stroke curves at elastic, transition and plastic zones. When the die radius increases, the whole curve follows, and the peak point of the curve will move backward. Both of them are conducive to improving the linear fitting correlation of the later curve. It can be seen from the groups of $30 \mathrm{~mm}-10 \mathrm{~mm}, 40 \mathrm{~mm}-20 \mathrm{~mm}$ and $40 \mathrm{~mm}-10 \mathrm{~mm}$, $50 \mathrm{~mm}-20 \mathrm{~mm}$, the former group internal die span is $20 \mathrm{~mm}$, later group internal die span is $30 \mathrm{~mm}$. the two curves in former or later group approach gradually in the later stage of bending.

It can be concluded from Figure 4 c) that the influence of thickness on the shape of curve is relatively little. It can be seen from Figure 4 d) that with different die radius and same die span, the curves coincident in elastic zone become longer, then 
the difference of yield loads extracted from transition zone is reduced. the different die radius effect on yield load is decreased naturally.
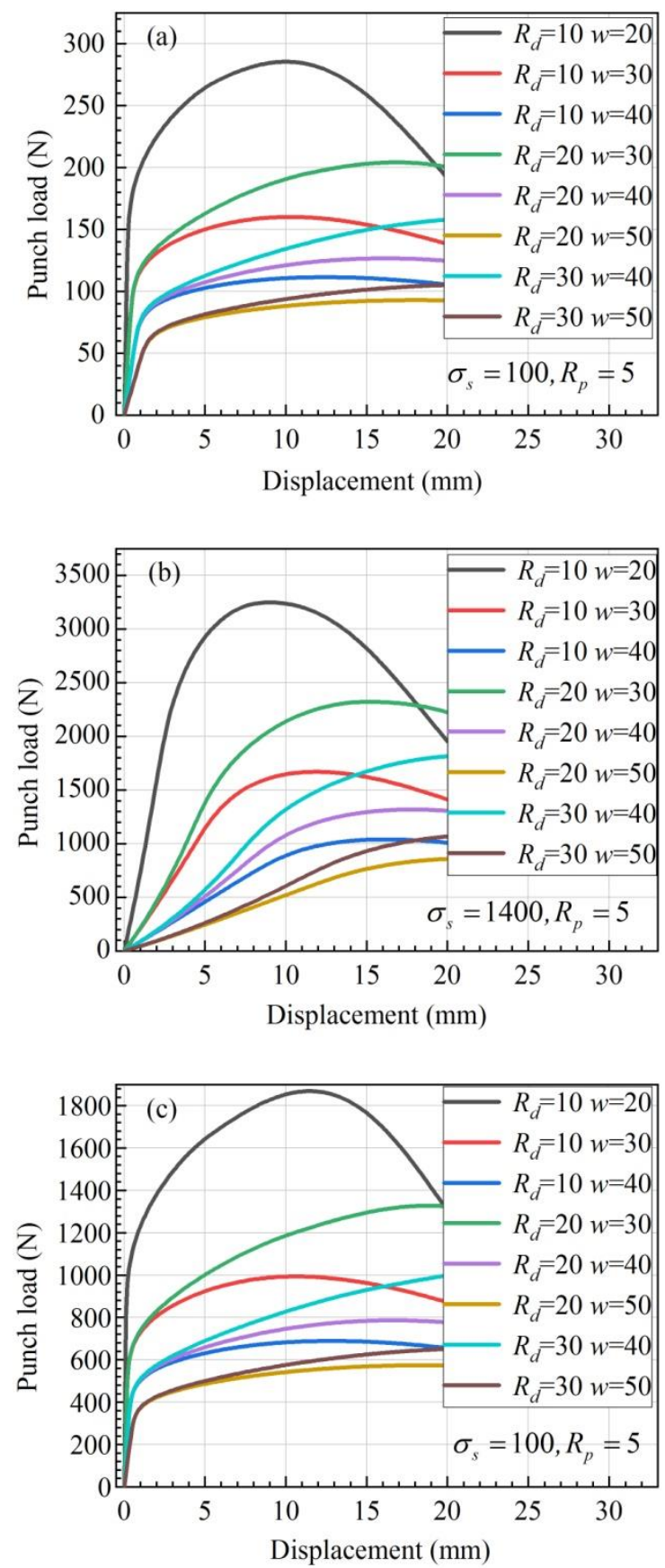

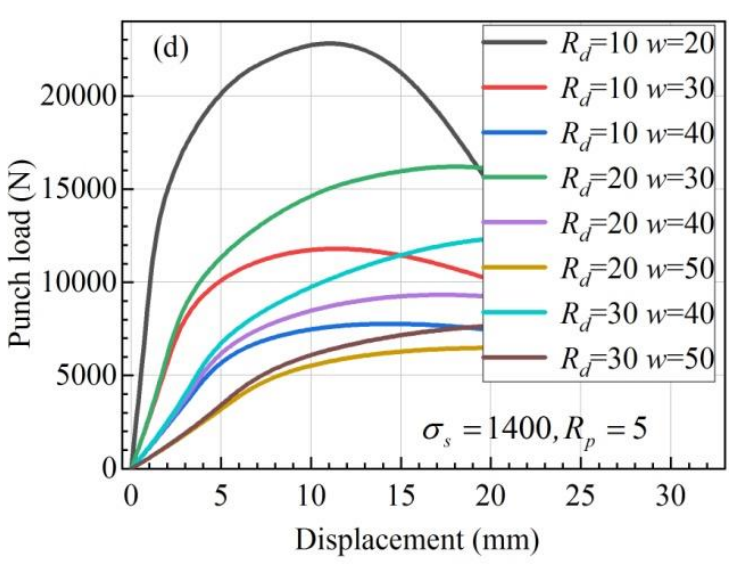

Figure 4.Curves of bending force travel under different spans and different die radius: a) $M Y L 1 \mathrm{~mm}$, b) $M Y H 1 \mathrm{~mm}$, c) $M Y L 2.35 \mathrm{~mm}$, d) MYH $2.35 \mathrm{~mm}$

To analyze the influence of different punch radii on the bending curve, several curves with different punch radii are presented in Figure 5. The punch radius is selected from $5 \mathrm{~mm}$, $6 \mathrm{~mm}, 7 \mathrm{~mm}, 8 \mathrm{~mm}$ and $9 \mathrm{~mm}$, respectively. The bending force stroke curve of a $M Y L$ material with $1 \mathrm{~mm}$ thickness is shown in Figure $5 \mathrm{a}$ ). Figure $5 \mathrm{~b}$ ) has provided the bending force stroke curve of a $M Y H$ material with a $1 \mathrm{~mm}$ thickness. The bending force stroke curve of a MYL material with a thickness of $2.35 \mathrm{~mm}$ material is shown in Figure $5 \mathrm{c}$ ). The bending force stroke curve of a $M Y H$ material with a thickness of $2.35 \mathrm{~mm}$ material is illustrated in Figure 5d).

In the initial stage of bending, the sheet deforms less and the curvature radius under the punch is large. The contact between the punch and the sheet metal is line contact or micro surface contact, the different radii have little effect on the curve. Along with the rises in the bending stroke, the curvature radius of the sheet metal is gradually consistent with punch radius. When the curvature radius of the sheet is no longer reduced due to the limitation of the punch, the plastic deformation extends out, and the bending force stroke curve goes up in the later period. The larger the fillet radius is, the greater the rise is, but the rising is very low. It can tell from the comparison of the four figures that when the thickness increase, the branch point moves forward. When the yield strength increases, the branch point moves backward. 

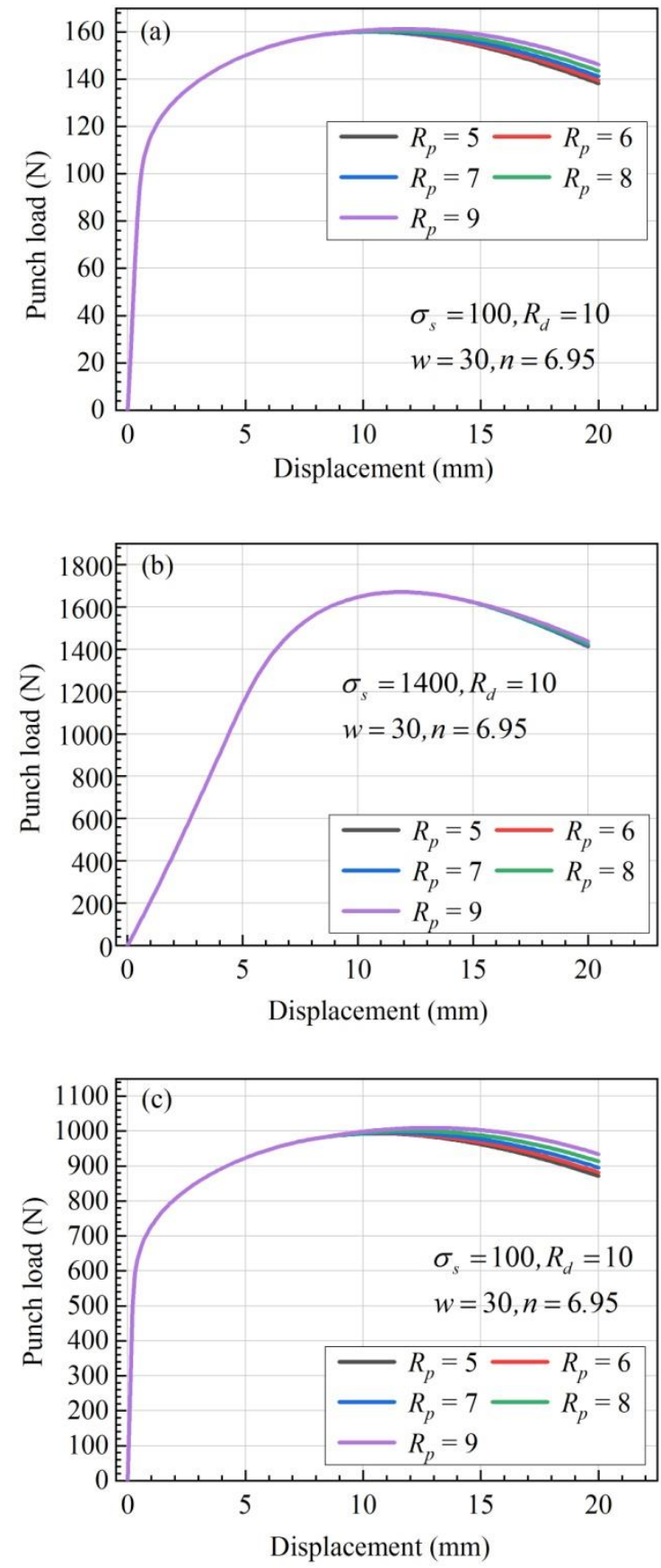

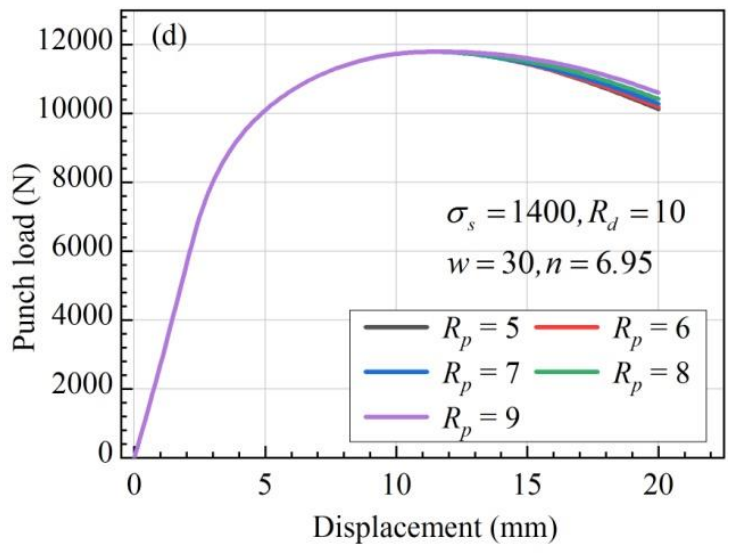

Figure 5.Curves of bending force stroke under different punch radius: a) MYL 1mm, b) $M Y H 1 \mathrm{~mm}$, c) $M Y L 2.35 \mathrm{~mm}$, d) $M Y H 2.35 \mathrm{~mm}$

To sum up, the increase of die span and die radius in test device can flatten the force stroke curve in plastic zone, which is conducive to algorithm identification, but lengthen the sample. The $M Y H$ materials introduce nonlinearity in the elastic zone and increase the curve curvature in the plastic zone, yield strength increasing is bad for identification, thickness increasing is good for identification. When the sheet completely contacts the punch, the force stroke curve can be slightly raised. When the thickness of sheet metal increases, the rising starting point moves forward. When the yield strength of the material increase, the branch point moves backward. Through the above analysis, a group of geometric parameters, including die span of $30 \mathrm{~mm}$, die radius of $20 \mathrm{~mm}$ and punch radius of $5 \mathrm{~mm}$, are selected in the subsequent identification experiments.

\subsection{Identification methodology}

Through the above analysis, when the sheet thickness changes, the yield load based on bending also varies accordingly. Referring to literature, the yield strength is assumed to be a binary function related to the yield load and thickness, shown as Formula 4. Subsequently, its correlation is further analyzed .

$$
\sigma_{\mathrm{s}}=f\left(P_{y}, t\right)
$$

However, the correlation methods have the following problems:

(1) Through the above analysis, a better geometric combination of the test device has been selected, but in essence, the force stoke curve is the comprehensive reflection of the material behavior. The yield load extracted from transition curve is only related to the yield strength of the material, and the corresponding mathematical relation cannot be directly 
provided through the mechanism.

(2) The yield load and yield strength are correlated, but algorithms or other parameters should also be introduced to reduce correlation equation scattering.

(3) The yield load extracted by different identification algorithms are various, so it is of great necessity to analyze the accuracy and dispersion of the identification results, relatively stable identification algorithm need to be determined. In this way, the yield strength can be objectively and consistently identified.

Four identification methods are shown as follow, t/10 and double secant line method refer to literature[27], window vector method and standardized fitting residual method are proposed in this paper.

\section{a) t/10 method[27]}

The sheet thickness have greater influence on the force stroke curve. $t / 10$ method refers to the method which is used to determine the yield strength of the stress-strain curve from the uniaxial tensile test. A line is determined by fitting data in elastic zone. then the line keep parallel and moves to right. The load at the intersection of the right line and the load curve is define as $P_{y_{-} / 10}$. The typical determination process is shown in Figure 6.

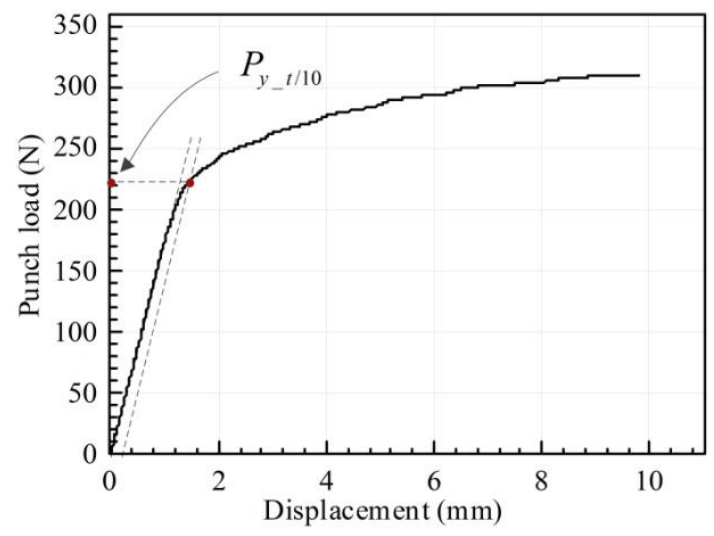

Figure 6. t/10 method to calculate yield load

\section{b) "Double Secant Line" Method (CWA) [27]}

The force stroke data before the maximum load point are extracted, and curve is depicted as shown in Figure 7. Two straight lines are fitted by least square method. The turning point coordinates are denoted as $\left(h_{y}, P_{y}\right)$, and the fitting equation is constructed as follows:

$$
P= \begin{cases}\frac{P_{y}}{h_{y}} h & h \leq h_{e} \\ k\left(h-h_{y}\right)+P_{y} & h \geq h_{e}\end{cases}
$$

The first line reflects the elastic deformation behavior, and the second line demonstrates the plastic deformation behavior. The intersection point of the two secant lines is defined as the yield load $P_{y_{-} C W A}$. The least square method is implemented to fit the above equation to minimize the error.

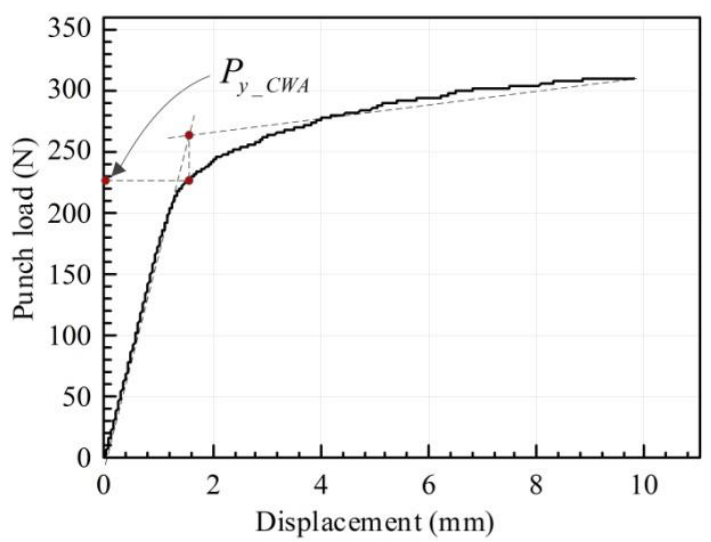

Figure 7.CWA method to calculate yield load

\section{c) Window Vector Method (WV)}

Firstly, the experimental data are filtered by least squares smoothing, and the corner angle $\alpha_{0}$ of the experimental data are extracted by cross window vector $A$ and $B$. Later, the angle data was filtered by least squares smoothing. Finally, the yield load $P_{y_{-} W V}$ at the maximum angle is extracted. The typical determination process is shown in Figure 8.

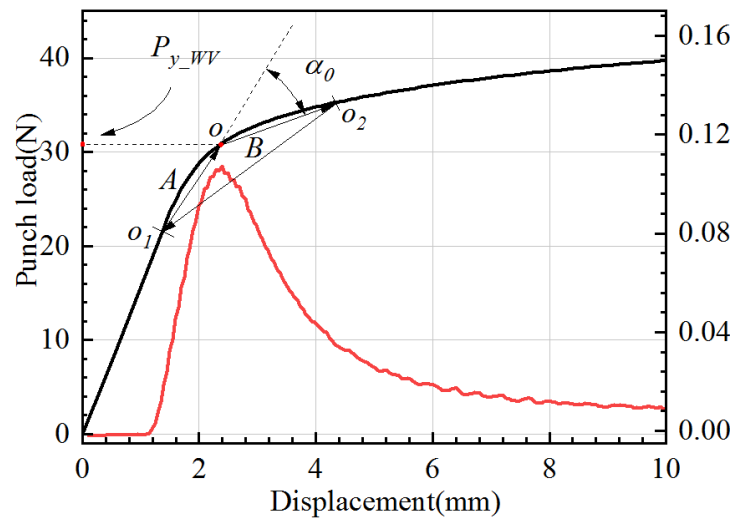

Figure 8.WV method to calculate yield load

\section{d) Standardized Fitting Residual Method (SFR)}

Firstly, the force stroke data are extracted as the continuous 
column data set, All data before the current row $i$ are linearly fitted, and the residual is output at the current point. The ratio of the sum which is calculated by adding the square of the residual before the current point to the sum which is obtained by adding the square of the load value before the current point is calculated. When the ratio exceeds a set threshold, it means that the turning point of the force stroke curve has been reached. The equation is shown as equation 6 . The determined yield load $P_{y_{S} S F R}$ is shown in Figure 9.

$$
P_{y}=\min \left\{\begin{array}{l}
P_{i}: i \in[3,4,5 \ldots, m] \\
\mid \sum_{1}^{i}\left[P_{i}-\left(k h_{i}+b\right)\right]^{2} / \sum_{1}^{i} P_{i}^{2} \geq C
\end{array}\right\}
$$

In the formula, $m$ is the total number of data points of the curve, $k$ is the slope after fitting the straight line, $\mathrm{b}$ is the intercept of the straight line after fitting, and $C$ is the set threshold of the SFR method

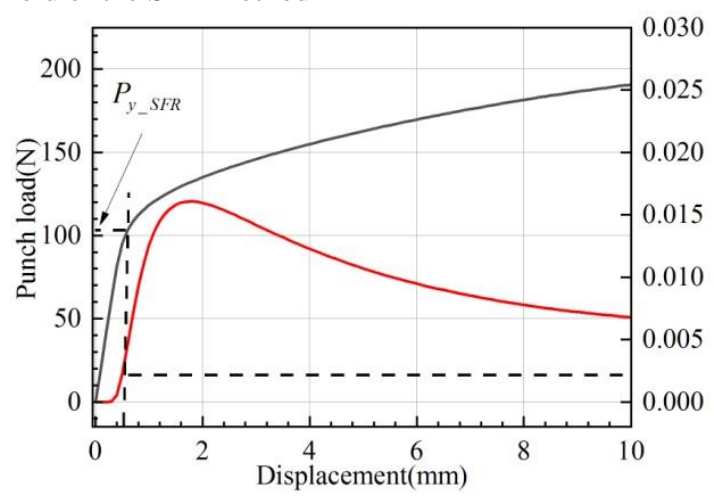

Figure 9.SFR method to calculate yield load

\section{Identification and correlation analysis}

Through the analysis, it can be found that the yield strength and thickness of the material have great influence on the yield load, and the different hardening parameters also have certain effect on it. In order to fully analyze the adaptability of the above four algorithms for different materials and different thickness of sheet, 15 hypothetical materials are constructed by using the Ramberg constitutive model. The elastic modulus in the models is maintained at a constant value of $210000 \mathrm{MPa}$ and Poisson's ratio is 0.3. the materials are divided into five material groups (100 MPa, $400 \mathrm{MPa}, 700 \mathrm{MPa}, 1000 \mathrm{MPa}$ and $1400 \mathrm{MPa}$ ). Three Ramberg-Osgood coefficients $n$, namely, 6.95, 8.95 and 14 are selected from each material group, and the hardening index labels are N1, N2 and N3. All material parameter combinations and labels are listed in Table 1. The thickness is selected from $1 \mathrm{~mm}$ to $2.35 \mathrm{~mm}$ for analysis, and the thickness labels are T1-T10. After all material parameter combination discrete into stress and strain points that can be input in
ABAQUS, the bending mechanical model can be established by ABAQUS in which isotropic constitutive is applied to describe the hardening behavior of materials.

Table 1. Plastic properties of the hypothetical materials.

\begin{tabular}{cccccc}
\hline Material & $\sigma_{y}$ & $n$ & Material & $\sigma_{y}$ & $n$ \\
\hline M1.1 & 100 & 6.95 & M3.3 & 700 & 14 \\
M1.2 & 100 & 8.95 & M4.1 & 1000 & 6.95 \\
M1.3 & 100 & 14 & M4.2 & 1000 & 8.95 \\
M2.1 & 400 & 6.95 & M4.3 & 1000 & 14 \\
M2.2 & 400 & 8.95 & M5.1 & 1400 & 6.95 \\
M2.3 & 400 & 14 & M5.2 & 1400 & 8.95 \\
M3.1 & 700 & 6.95 & M5.3 & 1400 & 14 \\
M3.2 & 700 & 8.95 & - & - & - \\
\hline
\end{tabular}

\subsection{Yield load analysis}

In order to facilitate the analysis of the curves, four groups with different thickness are selected out of ten groups at equal intervals to analysis, and 60 force stroke curves are extracted and analyzed in combination with 15 kinds of hypothetical materials M1.1-M5.3. The materials with yield strength of $100 \mathrm{MPa}$ and thickness of $1 \mathrm{~mm}$ and $1.45 \mathrm{~mm}$ are illustrated in Figure $10 \mathrm{a}$ ), and the materials with yield strength of $100 \mathrm{MPa}$ and thickness of $1.9 \mathrm{~mm}$ and $2.35 \mathrm{~mm}$ are listed in Figure $10 \mathrm{~b}$ ). It can be concluded that under the same thickness, with the decrease of $n$ coefficient, the load curve gradually rises in plastic stage. Influenced by the force stroke curve in plastic zone, there is also a slight rise near the yield transition zone. It can be seen that $n$ have a certain effect on the identification of yield load. It can tell from Figure10 a) and b) that with the increase of thickness, the overall rise of load curve is higher, which generate greater influence of $n$ on yield load. Both the coefficient $n$ and the thickness have an effect on the yield load, while the thickness has a greater influence on extracted yield load.

As the yield strength is $400 \mathrm{MPa}$, the curves of bending force stroke under two thicknesses and three $n$ coefficients are shown in Figure $10 \mathrm{c}$ ) and $10 \mathrm{~d}$ ). The curve, as is being concluded, shifts with the increase of yield strength and thickness. Compared with Figure 10 a) and b), the overall shape of the curve varies little, but with the increase of yield strength, the obtained load is upward, and the yield load is positively related to the yield strength.

When the yield is $700 \mathrm{MPa}, 1000 \mathrm{MPa}$ and $1400 \mathrm{MPa}$, the force stroke curves under the two thicknesses and three $n$ coefficients are shown in Figure $10 \mathrm{e}$ ), f), g), h), i), j) respectively. With the increase of yield strength, the yield load 
goes up gradually, and the displacement here also follows this trend gradually. In the actual deformation, the increase of yield load and yield displacement on the curve is helpful for the algorithm to extract the characteristic load.

If the yield strength increases more than $700 \mathrm{MPa}$, there is slight nonlinearity of bending curve in elastic zone. Slight nonlinearity have some influence on the above four identification algorithms. The increase of thickness can enhance the bending stiffness, and maintain the force curve linear, in other words, it can decrease its nonlinearity. However, it still cannot eliminate the non-linear phenomenon. The following focuses on the analysis of the effect of different algorithms on the overall prediction accuracy.
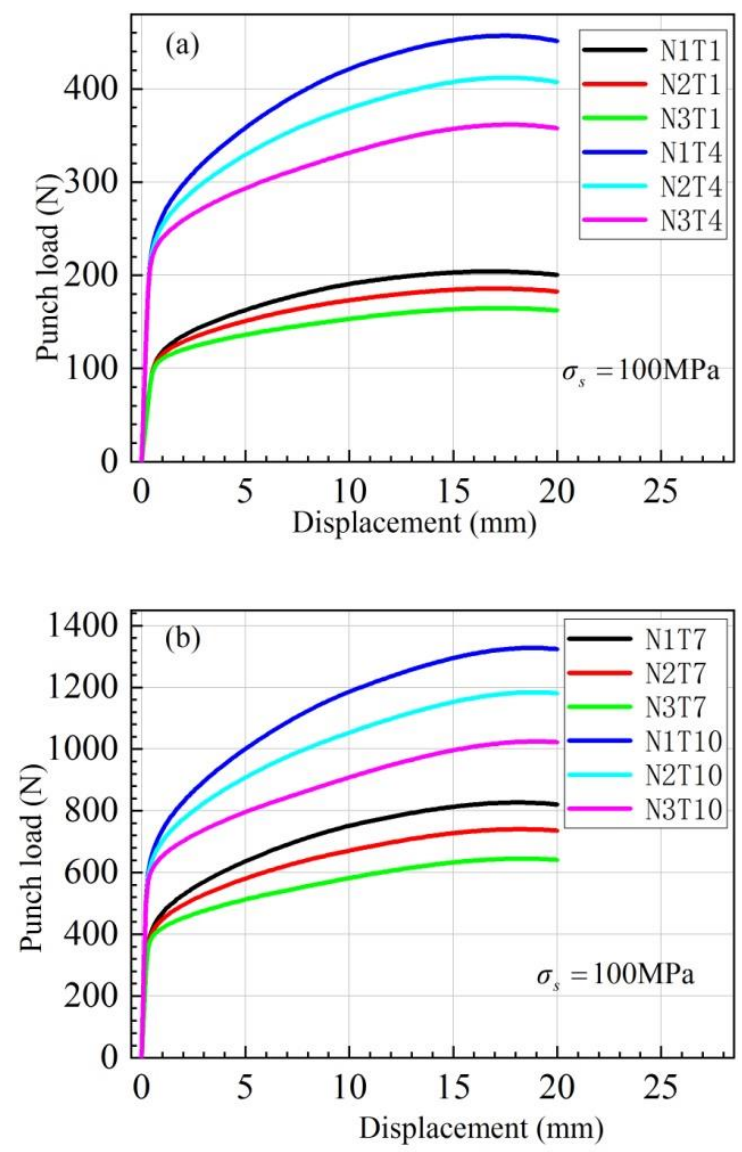
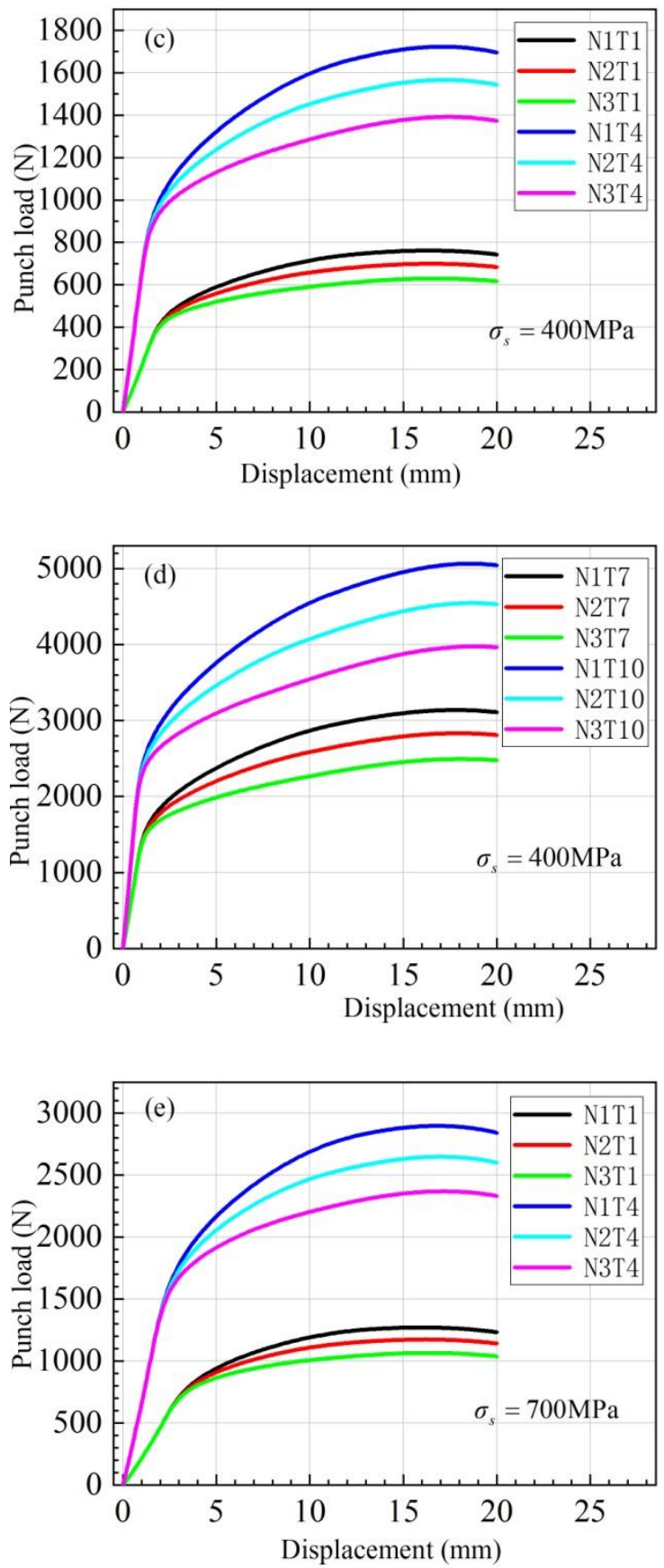

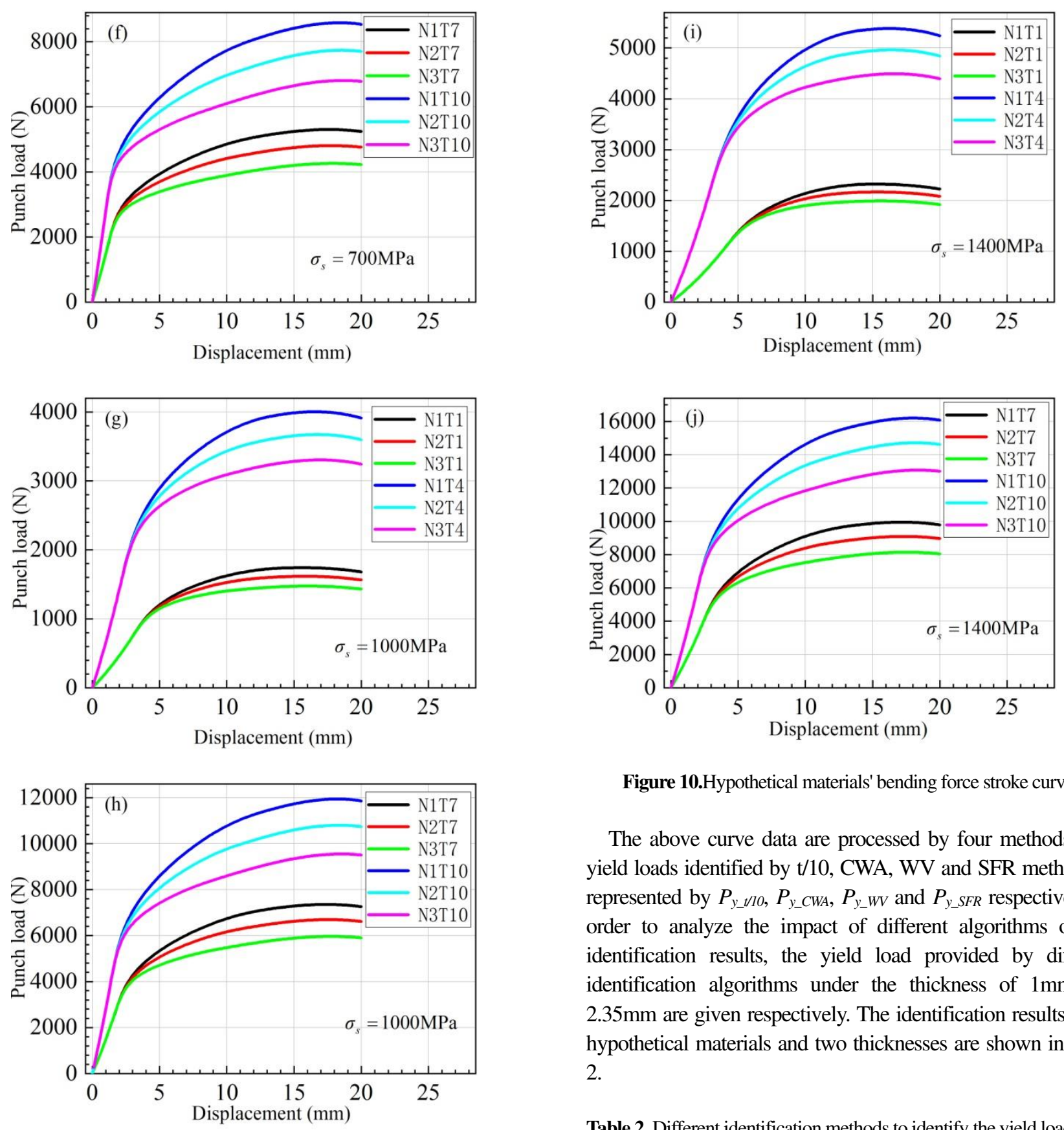

Figure 10.Hypothetical materials' bending force stroke curves

The above curve data are processed by four methods. The yield loads identified by $\mathrm{t} / 10, \mathrm{CWA}, \mathrm{WV}$ and SFR method are represented by $P_{y_{-} / I O}, P_{y_{-} C W A}, P_{y_{-} W V}$ and $P_{y_{-} S F R}$ respectively. In order to analyze the impact of different algorithms on the identification results, the yield load provided by different identification algorithms under the thickness of $1 \mathrm{~mm}$ and $2.35 \mathrm{~mm}$ are given respectively. The identification results of 15 hypothetical materials and two thicknesses are shown in Table 2.

Table 2. Different identification methods to identify the yield load of hypothetical materials.

\begin{tabular}{cccccc}
\hline Materials & Thickness(mm) & $\begin{array}{c}P_{y_{-} t / 10} \\
(\mathrm{~N})\end{array}$ & $\begin{array}{c}P_{y_{-} C W A} \\
(\mathrm{~N})\end{array}$ & $\begin{array}{c}P_{y_{-} W V} \\
(\mathrm{~N})\end{array}$ & $\begin{array}{c}P_{y_{-} S F R} \\
(\mathrm{~N})\end{array}$ \\
\hline M1.1 & 1 & 103.42 & 113.45 & 108.39 & 103.04 \\
M1.2 & 1 & 101.83 & 108.5 & 106.67 & 101.13 \\
M1.3 & 1 & 99.44 & 102.48 & 106.83 & 98.98 \\
M2.1 & 1 & 446.92 & 485.92 & 427.24 & 457.54 \\
M2.2 & 1 & 433.98 & 462.50 & 431.48 & 443.41 \\
M2.3 & 1 & 419.13 & 434.58 & 430.08 & 427.2 \\
\hline
\end{tabular}




\begin{tabular}{lccccc}
\hline M3.1 & 1 & 896.31 & 890.26 & 787.5 & 871.89 \\
M3.2 & 1 & 853.76 & 846.43 & 775.39 & 835.49 \\
M3.3 & 1 & 807.43 & 793.12 & 769.73 & 794.99 \\
M4.1 & 1 & 1437.07 & 1308.6 & 1137.11 & 1326.34 \\
M4.2 & 1 & 1344.7 & 1245.77 & 1135.55 & 1258.39 \\
M4.3 & 1 & 1247.05 & 1168.53 & 1123.63 & 1187.5 \\
M5.1 & 1 & 2194.43 & 1870.97 & 1625.98 & 1952.77 \\
M5.2 & 1 & 2035.03 & 1781.57 & 1637.11 & 1840.13 \\
M5.3 & 1 & 1861.62 & 1674.96 & 1598.83 & 1723.54 \\
M1.1 & 2.35 & 662.61 & 652.33 & 645.28 & 589.93 \\
M1.2 & 2.35 & 640.16 & 613.41 & 627.24 & 572.00 \\
M1.3 & 2.35 & 609.8 & 572.61 & 602.09 & 552.56 \\
M2.1 & 2.35 & 2527.86 & 2728.61 & 2453.06 & 2395.22 \\
M2.2 & 2.35 & 2447.67 & 2554.01 & 2404.99 & 2328.64 \\
M2.3 & 2.35 & 2355.01 & 2357.08 & 2340 & 2252.01 \\
M3.1 & 2.35 & 4552.8 & 4963.81 & 4273.05 & 4430.13 \\
M3.2 & 2.35 & 4383.2 & 4624.6 & 4303.91 & 4272.73 \\
M3.3 & 2.35 & 4187.73 & 4245.81 & 4180.08 & 4085.69 \\
M4.1 & 2.35 & 6856.73 & 7324.15 & 6184.38 & 6685.55 \\
M4.2 & 2.35 & 6532.57 & 6798.46 & 6068.75 & 6377.49 \\
M4.3 & 2.35 & 6179.85 & 6230.12 & 6028.52 & 6056.37 \\
M5.1 & 2.35 & 10434.33 & 10631.83 & 8713.28 & 9959.02 \\
M5.2 & 2.35 & 9784.88 & 9828.86 & 8724.22 & 9402.49 \\
\hline & 2.35 & 9112.00 & 8969.47 & 8491.41 & 8833.04 \\
\hline
\end{tabular}

In the above table, the yield strength is changed each three rows, the rows from 1 to 15 are the sheet materials of $1 \mathrm{~mm}$ thickness and the rows from 16 to 30 are the sheet materials of $2.35 \mathrm{~mm}$ thickness. For low yield strength material of $1.00 \mathrm{~mm}$ thickness, as $n$ coefficient goes upwards, the identification yield load go downward. The range of yield load extracted by $t / 10$ method is about $4 \mathrm{~N}$, The range for CWA method is about $11 \mathrm{~N}$, and The range for $\mathrm{WV}$ is about $1.6 \mathrm{~N}$, and range for SFR is about $4 \mathrm{~N}$.

For low yield strength material of $2.35 \mathrm{~mm}$ thickness, the yield load range of t/10 method, CWA method, WV method and SFR method are about $53 \mathrm{~N}, 80 \mathrm{~N}, 43 \mathrm{~N}$ and $37 \mathrm{~N}$, respectively. When the yield is low, the results identified by $t / 10$ method are least affected by different $n$ coefficients, while the WV method is highly affected by different $n$ coefficients. For high yield strength material of $1.00 \mathrm{~mm}$ thickness, the load range value of t/10 method, CWA method, WV method and SFR method are about 333N, 196N, 27N, and 229N, respectively.

For high yield strength material of $2.35 \mathrm{~mm}$ thickness, the load range value of t/10 method, CWA method, WV method and SFR method are about $1332 \mathrm{~N}, 1662 \mathrm{~N}, 222 \mathrm{~N}$ and1126N, respectively. When the yield is high, the results identified by WV method are the least affected by different $n$ coefficients, and the results identified by CWA method are the most affected by different $n$ coefficients.

When the yield strength of material is low, the yield stroke is relatively low too. Under the same stroke interval, the output points of testing machine and the finite element simulation are relatively less, while the $\mathrm{WV}$ method needs a certain window width, so the identification effect of WV method goes in different way for $M Y L$ and $M Y H$ materials. The linearity of elastic zone of $M Y L$ material is better, so the $t / 10$ method has relatively low prediction dispersion. From the perspective of recognition mechanism, SFR and t/10 are similar, and the identified results tend to approach the beginning of transition curve, so the identified values of the two methods are lower. However, the results of the other two methods tend to be near the middle of transition curve. When the yield strength of the material increases, there is a certain nonlinearity in the elastic zone, but the dispersion of WV method is greatly reduced.
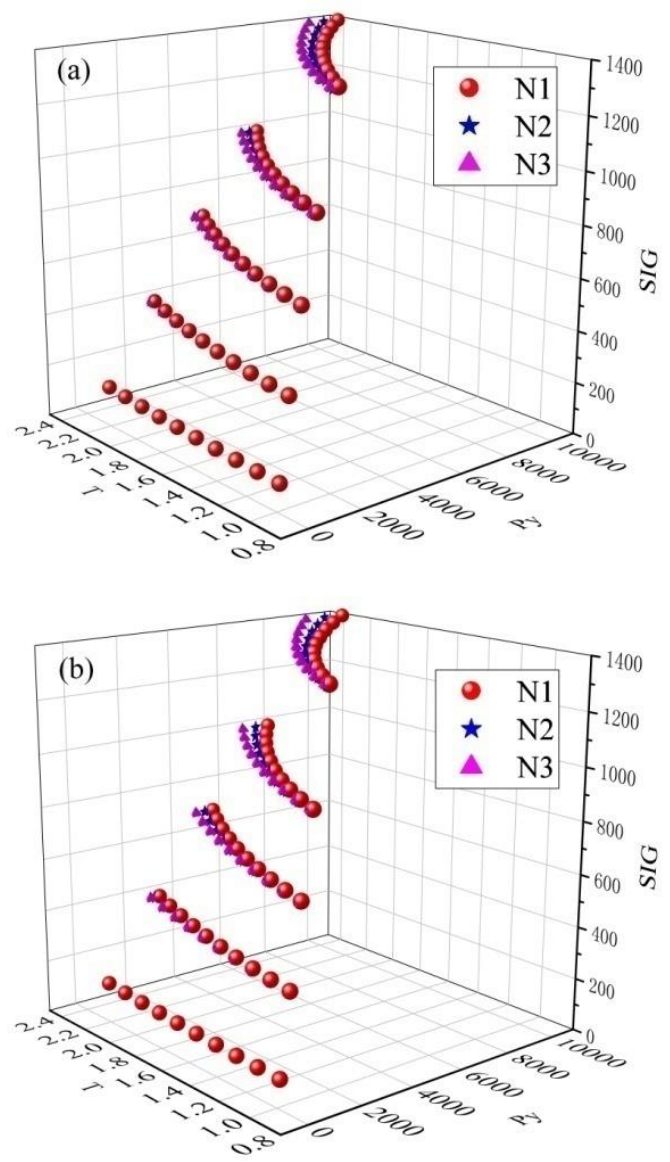

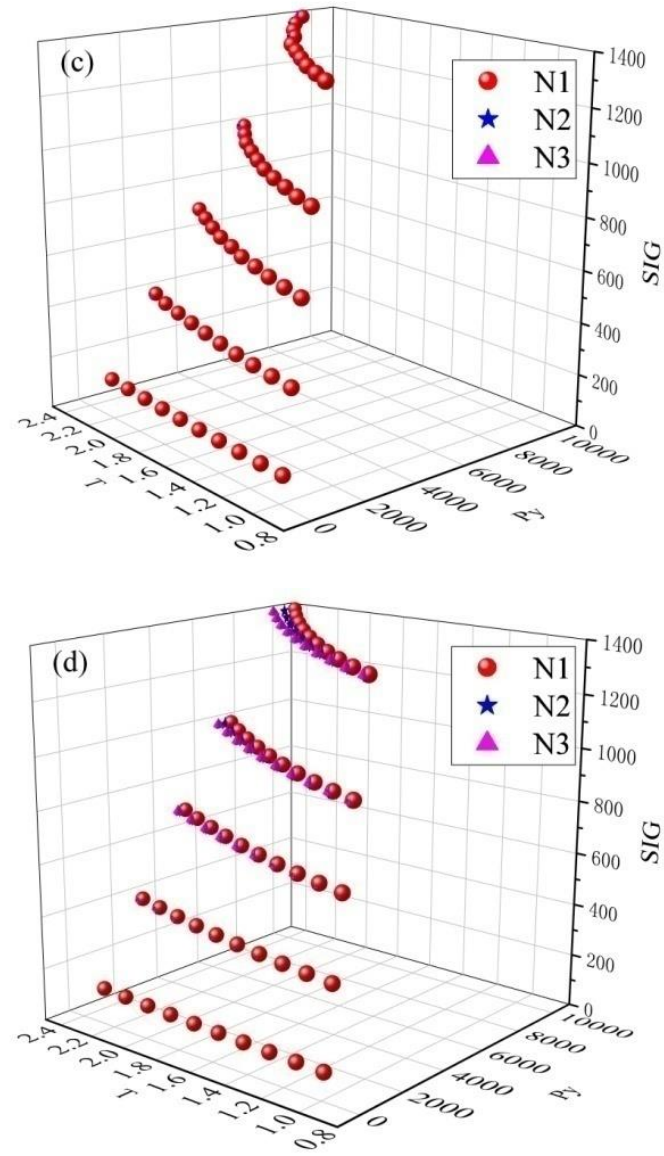

Figure 11. Yield load identified by different identification methods with different hardening index: a) t/10 method, b) CWA method, c) WV method, d) SFR method

Referring to Figure 11a), for low yield strength material, as the thickness rises, the yield loads identified by four methods are few varied, and yield load is linear with different thickness. By contrary, yield load identified by four methods have huge differences, and yield load is not linear with different thickness.

The yield load identified by $\mathrm{t} / 10$, WV and SFR methods gradually increase with yield strength. CWA method is most sensitive to yield strength. When the thickness increases, the dispersion of identified results by $t / 10$ and CWA goes upward with the influence of $n$. WV method is one of the four methods which show the least affection by $n$. It has a good anti-hardening interference ability.

\section{2 hypothetical material correlation analysis}

The influence of thickness and load on the yield strength should be taken into consideration comprehensively. The prediction model can be built on the basis of fitting the data given by the established finite element model. Through the analysis of the above data, the following equations are fitted respectively, and the obtained correlation coefficient can be seen from Table 3, Formula 7 only contains the first order term of thickness and yield load, Formula 8 adds the second order term of thickness on the basis of formula 7, formula 9 adds the cross term of load and thickness on the basis of formula 8 , formula 10 adds the third order term of thickness on the basis of formula 9, and least square method is used to fit the polynomial models respectively.

$$
\begin{gathered}
\sigma_{s}=a P_{y}+b t+c P_{y} t+d \\
\sigma_{s}=a P_{y}+b t+c P_{y} t+d+e t^{2} \\
\sigma_{s}=a P_{y}+b t+c P_{y} t+d+e t^{2}+f P_{y} t^{2} \\
\sigma_{s}=a P_{y}+b t+c P_{y} t+d+e t^{2}+f P_{y} t^{2}+g t^{3}
\end{gathered}
$$

Table 3. Correlation coefficients of different equations composed by different terms.

\begin{tabular}{ccccc}
\hline Formula & t/10 & CWA & WV & FR \\
\hline 7 & 0.941 & 0.929 & 0.945 & 0.939 \\
8 & 0.963 & 0.960 & 0.974 & 0.966 \\
9 & 0.979 & 0.981 & 0.994 & 0.985 \\
10 & 0.981 & 0.985 & 0.997 & 0.988 \\
\hline
\end{tabular}

The pure linear term model is fitted by the yield load which is identified by the four methods. maximum correlation coefficient is about 0.997 , minimum is about 0.929 . It can be seen that higher order terms should be added to describe its nonlinear behavior.

Through the data analysis, it can be concluded that the yield load determined by each method is positively related to the yield strength. Although it has a certain degree of dispersion, all yield strengths and yield load are approximately linear. After fitting the equation 10, the fitting surfaces using data extracted by the $\mathrm{t} / 10, \mathrm{CWA}, \mathrm{WV}$ and SFR methods are depicted in Figure 12 respectively. As the figure shows that the correlation coefficient of $t / 10$, CWA and SFR methods haven't exceeds 0.98 , and the correlation coefficient of WV method is about 0.99. It is the highest of the four methods, so the data extracted by WV method demonstrates to be very well fitted. 

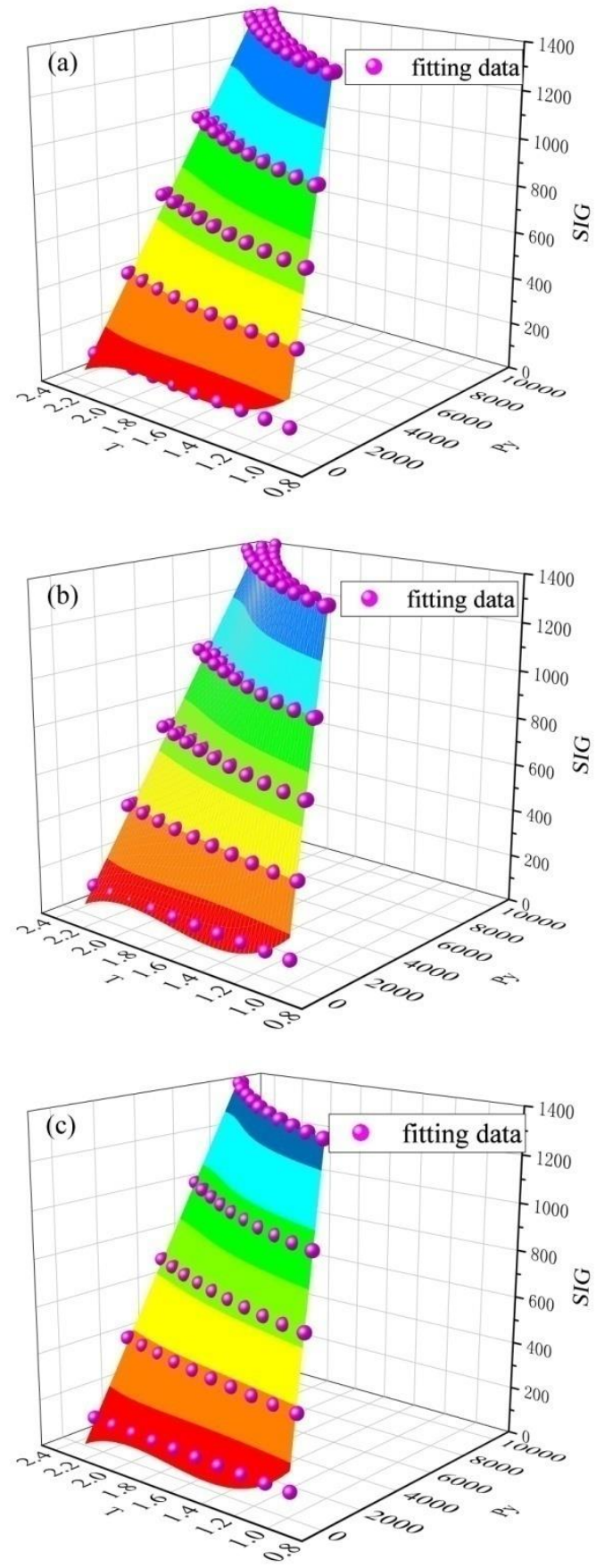

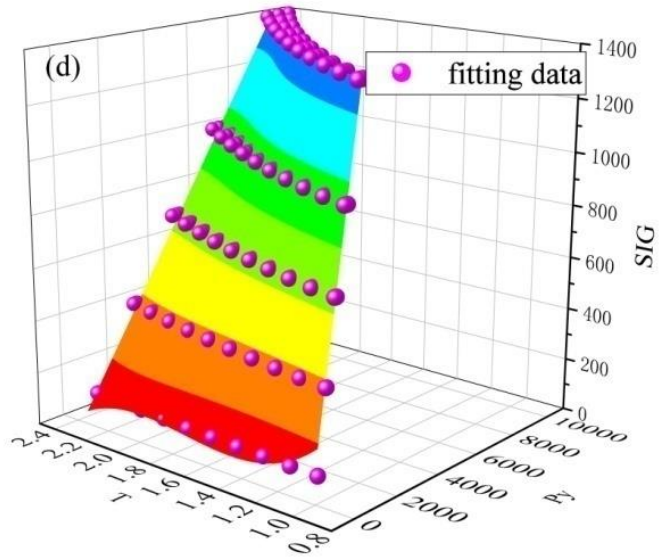

Figure 12. Fitting results of yield load identified by different identification methods: a) t/10 method, b) CWA method, c) WV method, d) SFR method

The fitting equations using yield loads identified by the four methods are Equations 11, 12, 13, and 14, respectively.

Fitting equation of $\mathrm{t} / 10$ method:

$$
\begin{aligned}
\sigma_{s}=1.471 P_{y} & -409.728 t^{3}+2120.251 t^{2} \\
-3550.35 t & +0.233 P_{y} t^{2}-1.114 P_{y} t \\
& +1999.054
\end{aligned}
$$

Fitting equation of CWA method:

$$
\begin{gathered}
\sigma_{s}=1.774 P_{y}-518.051 t^{3}+2691.285 t^{2} \\
-4494.451 t+0.293 P_{y} t^{2}-1.382 P_{y} t \\
+2439.325
\end{gathered}
$$

Fitting equation of WV method:

$$
\begin{gathered}
\sigma_{s}=1.942 P_{y}-504.933 t^{3}+2631.997 t^{2} \\
-4427.918 t+0.312 P_{y} t^{2}-1.489 P_{y} t \\
+2403.0
\end{gathered}
$$

Fitting equation of SFR method:

$$
\begin{gathered}
\sigma_{s}=1.684 P_{y}-466.597 t^{3}+2416.782 t^{2} \\
-4033.747 t+0.273 P_{y} t^{2}-1.295 P_{y} t \\
+2214.820
\end{gathered}
$$

Figure 13 shows the maximum deviation of predicted results of the yield strength by each method. It can be seen from the figure that the maximum deviation of predicted results by the four methods at the M1 group are higher than other groups. When the thickness is $1 \mathrm{~mm}$, the deviation of $\mathrm{t} / 10$ method exceeds $100 \%$. The deviation of the CWA and SFR methods is close to $90 \%$. Though the deviation of the WV method is relatively low, it is also nearly about $80 \%$. When the yield strength is small, the absolute value of the yield strength is low, and a slight dispersion increase the error. Meanwhile, if the yield strength is low, the elastic stroke is short, and a small stroke error results in the prediction error. When the stroke is 
small, only little interference can generate great influences on the result.

Among the materials of M2-M5, the maximum deviations of the yield strength predicted by the four methods is greatly reduced than that of the M1 material. However, with the increase of yield strength, the deviation of the prediction results did not alter much, indicating that the deviations of the predicted results of the four methods go upwards with the increase of yield strength.

When the yield strength of the material is in the range between M2-M5, no matter the increase of the yield strength or the increase of the thickness of the sheet, the overall deviation of predicted results of $t / 10$, CWA and SFR methods are relatively stable. Among them, the maximum deviation of the $\mathrm{t} / 10$ method at the maximum point is $13 \%$, the maximum deviation of the CWA method is $12 \%$, and the maximum deviation of the SFR method is $11 \%$. As the yield strength increases, the maximum deviation of the prediction of the WV method decreases in general. But as the thickness increases, the prediction deviation is relatively stable. The maximum deviation occurs in $\mathrm{M} 2$ materials, the deviation is about $7 \%$. Through the above comparison, it is found that the overall prediction result of the $\mathrm{WV}$ method is better than the other three methods in the range of M2-M5. However, for low yield strength materials, the prediction errors of the four methods are similar.

For this reason, a piecewise function is fitted by the results of the WV method. The fitted surface is shown in the figure 14, $100 \mathrm{MPa}-700 \mathrm{MPa}$ are in one group and $700 \mathrm{MPa}-1400 \mathrm{MPa}$ are in the other group, the fitted formula is shown in Equation 15. It can be seen from the Figure 14 that the deviation is decreased from the original $80 \%$ to about $20 \%$. The prediction deviation of M2 material is also decreased, but the prediction deviation of the M3 material has increased compared with the overall fitting. The maximum deviation is about $9 \%$.

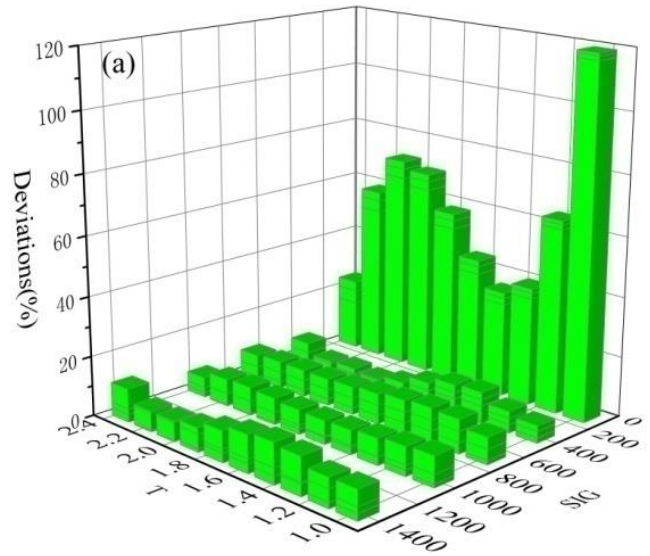

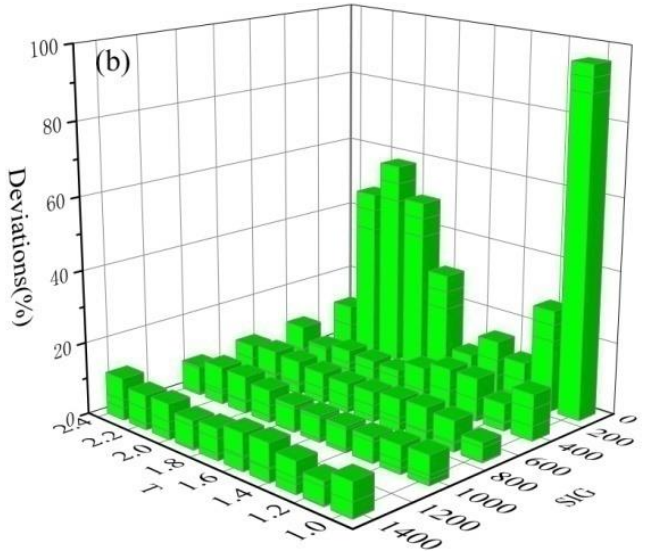
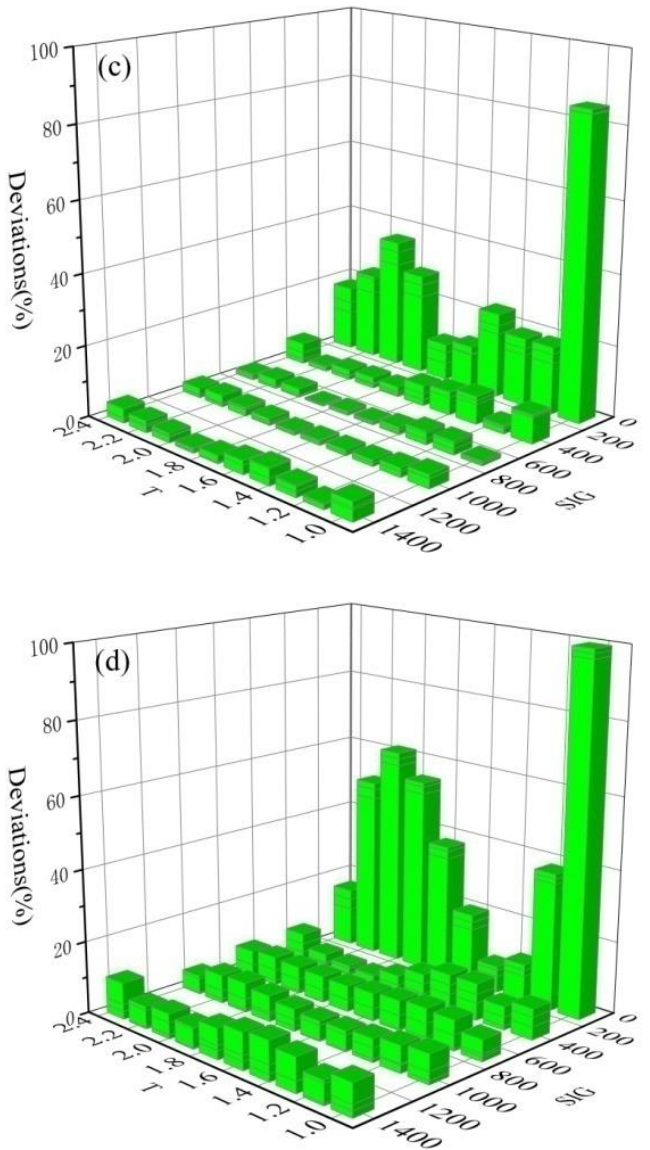

Figure 13.The deviation results of the yield load identified by different identification methods and the fitted surface: a) t/10 method, b) CWA method, c) WV method, d) SFR method 

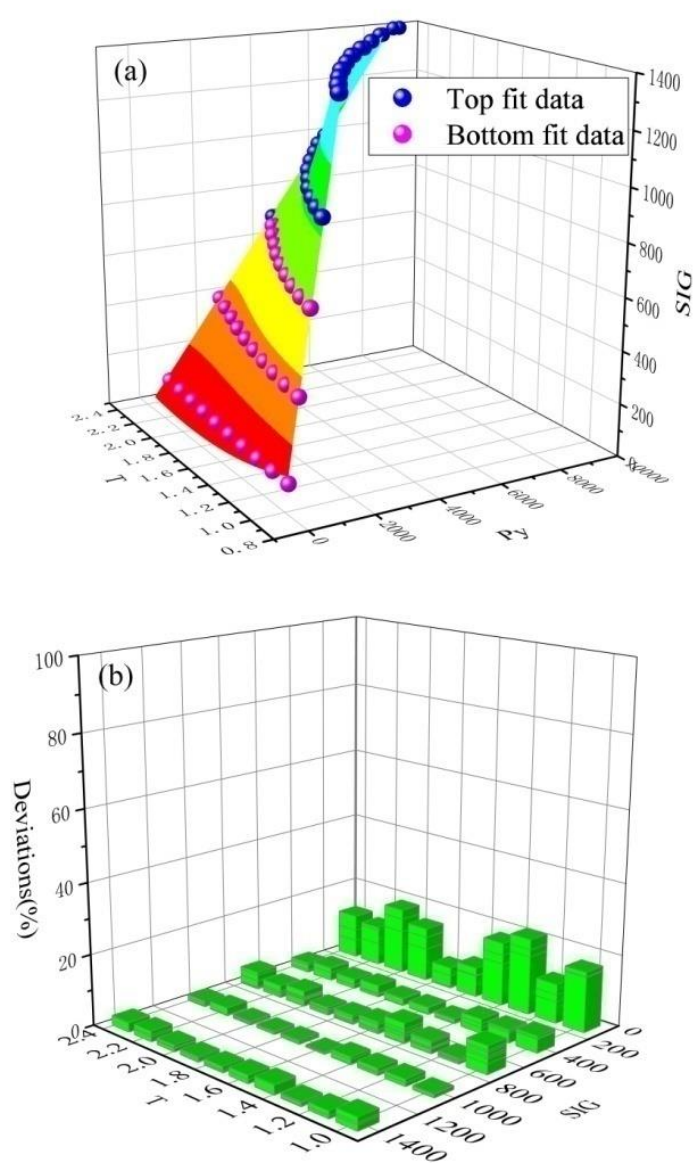

Figure 14. The deviation result between the yield load identified by the WV method and the piecewise fitted surface: a) fitted surface, b) maximum error

$$
\sigma_{s}= \begin{cases}2.17121 P_{y}-281.31615 t^{3}+1435.56426 t^{2} & \\ -2346.61413 t+0.36564 P_{y} t^{2} & P_{y} \leq 1500 \\ -1.70877 P_{y} t+1219.65673 & \\ 1.82977 P_{y}-663.24493 t^{3}+3480.60642 t^{2} & P_{y}>1500 \\ -5916.71133 t+0.28875 P_{y} t^{2} & \\ -1.38638 P_{y} t+3277.73265 & \end{cases}
$$

\section{Experiment and verification}

In order to verify the accuracy of the above methods, different yield strengths and thicknesses of sheets metal were implemented for bending verification experiments. In order to test the generalization error of the predicate model for the further application, six materials are selected for verification. Among the six materials, DP980 is a MYH material, DC06 and ST12 are MYL and high elongation materials, SUS304 and AL6061 are materials with medium yield strength, and aluminum alloy is non-ferrous metal. The mechanical properties of 6 materials are listed in the Table 4 . The table provides four parameters including the elastic modulus, yield strength, ultimate strength and rupture strain.

Table 4. Mechanical properties of experimental materials.

\begin{tabular}{ccccc}
\hline Materials & E (MPa $)$ & $\sigma_{s}(\mathrm{MPa})$ & $\sigma_{u_{\_} \text {eng }}(\mathrm{MPa})$ & $\mathcal{E}_{\text {fract }}$ \\
\hline DP980 & 141450 & 450 & 1128 & 0.181 \\
Al6061 & 57184 & 311 & 367 & 0.120 \\
SUS304 & 169914 & 286 & 1583 & 0.820 \\
ST12 & 123000 & 171 & 440 & 0.429 \\
DC04 & 120000 & 132 & 410 & 0.354 \\
DC06 & 120000 & 120 & 389 & 0.312 \\
\hline
\end{tabular}

The correlation model fitted in this paper also includes a variable $t$ which is sheet metal thickness. Through above analysis, the thickness has a small nonlinear effect on low yield strength of material, and has a large nonlinear effect on high yield strength of material, so different material and thickness are selected, nominal thickness and material are shown in Figure 15. The deviations between nominal thickness and the actual thickness are within $0.04 \mathrm{~mm}$.

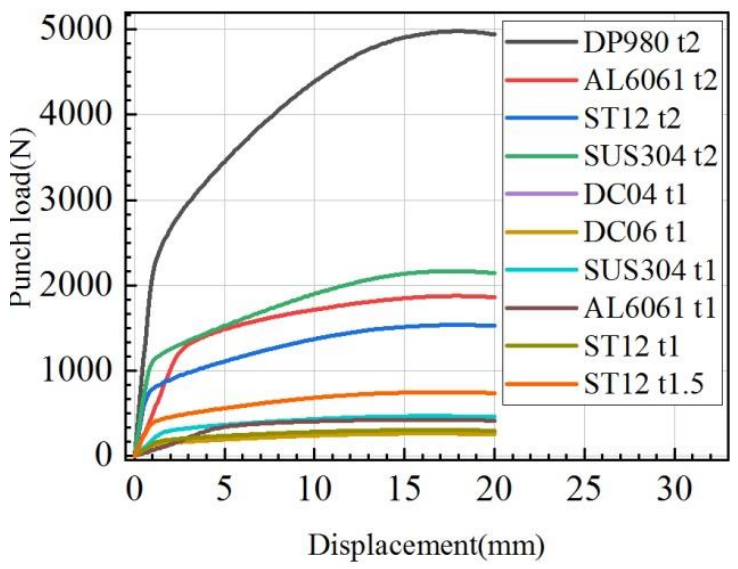

Figure 15. Bending force stroke curves of experimental materials

In order to increase the comparability between different materials, the bending force stroke curves of different materials are divided by the actual width of the bending specimen, and then it is multiplied by $35 \mathrm{~mm}$. It can be seen from the Figure 15 . DP980 has a higher yield load and a longer yield transition curve. DC06, ST12, AL6061 and SUS304 have larger curvature of the yield transition curves. Through above analysis, it has been found that WV method is better than the other three methods, and the dispersion affected by different hardening index is the lowest. The verification experiment uses the WV 
method to extract the yield load, and the final yield prediction errors are compared in Table 5.

Table 5 Yield load values identified by the wv method and yield strength values predicated by related model.

\begin{tabular}{cccc}
\hline Materials & Thickness(mm) & $P_{y_{-} w v}(\mathrm{~N})$ & $\sigma_{y_{-} w v}(\mathrm{MPa})$ \\
\hline DP980 & 2 & 2280.57 & 449.18 \\
Al6061 & 2 & 1270.51 & 298.83 \\
Al6061 & 1 & 340.31 & 309.09 \\
SUS304 & 2 & 1095.41 & 265.27 \\
SUS304 & 1 & 292.91 & 269.85 \\
ST12 & 2 & 759.57 & 172.40 \\
ST12 & 1.5 & 394.25 & 150.13 \\
ST12 & 1 & 177.23 & 174.05 \\
DC04 & 1 & 139.70 & 142.98 \\
DC06 & 1 & 127.12 & 132.56 \\
\hline
\end{tabular}

The predicted yield strengths from correlation models are compared with the yield strengths from the uniaxial tensile test. The predicted deviations of the yield strengths of sheets with different thicknesses and different materials are shown in Figure 16 , which shows that changes in material type and thickness can cause corresponding changes in prediction error. Among them, ST12, DC04, and DC06 are MYL materials, when the prediction deviation is equivalent to other materials, the relative error of prediction is relatively high compared with other methods. The ST12, DC06, and DC04 material prediction errors are about $12 \%, 9 \%$, and $8 \%$, respectively, and the ST12 prediction error is the largest. The AL6061 and SUS304 are materials with medium yield strength. The maximum error of SUS304 is about 7\%. The yield strength of AL6061 has increased relative to SUS304. Therefore, the maximum error of AL6061 is about 4\%. DP980 is a MYH material with a prediction error within $1 \%$. This paper uses yield load from hypothetical material to fit the correlation model. If the experimental data of actual materials are used, the absolute prediction accuracy of the prediction model can be further improved. Even if the experimental data is not added the correlation model, current prediction accuracy is acceptable. Under most of industries condition, the relative change in the yield strength of material are needed more than absolute value. The calculation consumption of fitting prediction model is greatly reduced, the prediction efficiency is improved, so this method is beneficial for online rating of materials efficiently. In addition, it is very convenient to embed the equations into chip to make a material yield performance recognition sensor, and then the feed forward or feedback method can be further applied to control the consistency of the product.

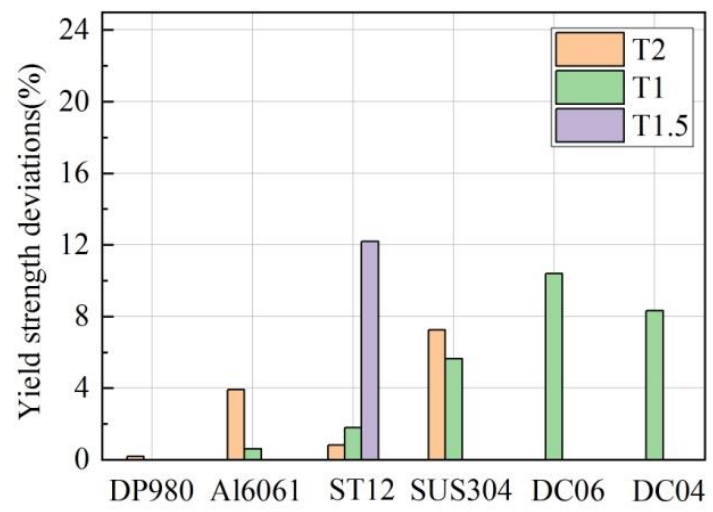

Figure 16.The deviation results of the yield strengths identified for different materials

\section{Conclusion}

Bending deformation is used to study the identification of yield strength for the first time, the conclusions are obtained as follows:

1. The yield characteristics on the bending force stroke curve are comprehensively affected by various factors, higher yield and lower thickness cause the nonlinearity in the elastic zone and weaken the yield characteristics. Larger thickness and wider die span strengthen the yield characteristics. The hardening index increases the dispersion of the identified yield load. A set of geometric parameters are determined: the die span is $30 \mathrm{~mm}$, the die radius is $20 \mathrm{~mm}$, and the die radius is $5 \mathrm{~mm}$.

2. The WV and the SFR method are proposed and compared with the CWA and t/10 methods. Through the study found that the proposed WV method can get better effect to eliminate dispersion with different hardening indexes. A new correlation model added independent thickness variable is fitted by identified yield loads to eliminate the dispersion caused by the change of thickness. Finally, the piecewise function fitted by the yield loads extracted from the WV method shows a better correlation. The maximum deviation error is decreased from the $80 \%$ to about $20 \%$.

3. The experimental data is used to verify the generalization error of fitted correlation model. ST12, DC04, DC06 are grouped as MYL materials, the prediction errors of ST12, DC06, DC04 are about 12\%, 9\%, and 8\%. The AL6061 and SUS304 are materials with medium yield strength, the maximum error of SUS304 and AL6061 are about 7\%, 4\%, respectively. DP980 is a $M Y H$ material with a prediction error within $1 \%$. This method is very helpful for online 
rating of materials efficiently.

\section{Declaration}

\section{Acknowledgements}

This work is partially supported by National Natural Science Foundation of China (51705448), Hebei Natural Science Foundation (E2018203100), Doctoral Foundation of Yanshan University (B861) and Youth Teachers Independent Research Foundation of Yanshan University (15LGB002). The authors also gratefully acknowledge the helpful comments and suggestions of the reviewers, which have improved the presentation.

\section{Author Contributions}

Y.D. conceived and designed the experiments, H.Q. performed the experiments and built the software. F.Z. proved the validity. Y.D. wrote the original draft. Y.D. and H.Q. reviewed and edited the article. Y.D., H.Q. and Y.L. finished the visualization. L.T., L.Y. and Y.G. put forward suggestions for modification. Y.D., F.Z. and Y.G. provided project administration. All authors have read and agreed to the published version of the manuscript.

\section{Funding}

This research was funded by National Natural Science Foundation of China (51705448), Hebei Natural Science Foundation (E2018203100), Doctoral Foundation of Yanshan University (B861) and Youth Teachers Independent Research Foundation of Yanshan University (15LGB002).

\section{Conflicts of Interest}

The authors declare no conflict of interest. The funders had no role in the design of the study; in the collection, analyses, or interpretation of data; in the writing of the manuscript; or in the decision to publish the results.

\section{Availability of data and materials}

The raw/processed data required to reproduce these findings cannot be shared at this time due to technical or time limitations.

\section{Consent for publication}

Not applicable

\section{Ethics approval and consent to participate}

Not applicable

\section{Reference}

[1] M. Yang, K.I. Manabe, H. Nishimura. Development of Real-time Process Control System for Precision and Flexible V-bending with an On-line
Database [J]. Journal of Materials Processing Technology, 60(1) (1996) 249-254.

[2] M.L. Garcia-Romeu, J. Ciurana, I. Ferrer, et al. Springback Determination of Sheet Metals in an Air Bending Process Based on an Experimental Work [J]. Journal of Materials Processing Technology, 191(1-3) (2007) 174-177.

[3] H. Karbasian, A.E. Tekkaya. A Review on Hot Stamping [J]. Journal of Materials Processing Technology, 210(15) (2010) 2103-2118.

[4] C. Suppan, T. Hebesberger, A. Pichler, et al. On the Microstructure Control of the Bendability of Advanced High Strength Steels [J].Materials Science and Engineering A, 735 (2010) 89-98.

[5] Mohammad Albakri, Fadi Abu-Farha, Marwan Khraisheh. A New Combined Experimental-Numerical Approach to Evaluate Formability of Rate Dependent Materials [J]. International Journal of Mechanical Sciences, 66 (2013) 55-66.

[6] Markus Kaupper, Marion Merklein. Bendability of advanced high strength steels-A new evaluation procedure [J]. CIRP Annals-Manufacturing Technology, 62(1) (2013) 247-250.

[7] D. Rèche, T. Sturel, O. Bouaziz, et al. Damage Development in Low Alloy TRIP-aided Steels during Air-bending [J]. Materials Science and Engineering A, 528(15) (2011) 5241-5250.

[8] A. Pradeau, S. Thuillier, J.W. Yoon. Prediction of Failure in Bending of an Aluminium Sheet Alloy[J]. International Journal of Mechanical Sciences, 119 (2016) 23-35.

[9] Laurent Mattei, Dominique Daniel, Gilles Guiglionda, et al. Strain Localization and Damage Mechanisms during Bending of AA6016 Sheet [J]. Materials Science and Engineering A,559 (2013) 812-821.

[10] Guosong Lin, S. Jack Hu, Wayne Cai. Evaluation of Formability in Bending/Hemming of Aluminum Alloys Using Plane-Strain Tensile Tests [J]. Journal of Manufacturing Science and Engineering, 131(5) (2009) 051009.

[11] A. Pradeau, S. Thuillier, J.W. Yoon. Prediction of Failure in Bending of an Aluminium Sheet Alloy [J]. International Journal of Mechanical Sciences, 119 (2016) 23-35

[12] D.Y. Yang, M. Bambach, J. Cao, et al. Flexibility in Metal Forming [J] CIRP Annals-Manufacturing Technology, 67(2) (2018) 743-765.

[13] Jinjin Ha, Myoung-Gyu Lee, FrédéricBarlat. Strain Hardening Response and Modeling of EDDQ and DP780 Steel Sheet under Non-linear Strain Path [J]. Mechanics of Materials, 64 (2013) 11-26.

[14] Jos Havinga, Ton van den Boogaard, Franz Dallinger, et al. Feedforward Control of Sheet Bending Based on Force Measurements [J]. Journal of Manufacturing Processes, 31 (2018) 260-272.

[15] S. Bruschi, T. Altan, D. Banabic, et al. Testing and Modelling of Material Behaviour and Formability in Sheet Metal Forming [J]. CIRP Annals-Manufacturing Technology, 63(2) (2014) 727-749.

[16] J.A. Canteli, J.L. Cantero, M.H. Miguélez. Experimental Identification of a Thermo-mechanical Model for Air Bending [J]. Journal of Materials Processing Technology, 203(1-3) (2008) 267-276.

[17] Y.G. An, H. Vegter, J. Heijne. Development of Simple Shear Test for the Measurement of Work Hardening [J]. Journal of Materials Processing Technology, 209(9) (2009) 4248-4254.

[18] J.M. Allwood, S.R. Duncan, J. Cao, et al. Closed-loop Control of Product Properties in Metal Forming [J]. CIRP Annals-Manufacturing Technology, 65(2) (2016) 573-596.

[19] Ming Yang. Smart Metal Forming with Digital Process and IoT [J]. International Journal of Lightweight Materials and Manufacture, 1(4) (2018) 207-214.

[20] G. Simons, Ch. Weippert, J. Dual, et al. Size Effects in Tensile Testing of Thin Cold Rolled and Annealed Cu Foils [J]. Materials Science and Engineering A, 4196(1-2) (2006) 290-299.

[21] A. Nasser, A. Yadav, P. Pathak, et al. Determination of the flow stress of 
five AHSS sheet materials (DP 600, DP 780, DP 780-CR, DP 780-HY and TRIP 780) using the uniaxial tensile and the biaxial Viscous Pressure Bulge (VPB) tests [J]. Journal of Materials Processing Technology, 210(3) (2010) 429-436.

[22] Alan Hannon, Peter Tiernan. A Review of Planar Biaxial Tensile Test Systems for Sheet Metal [J]. Journal of Materials Processing Technology, 198(1-3) (2008) 1-13

[23] David Lecompte, Arwen Smits, Hugo Sol, et al. Mixed Numerical-Experimental Technique for Orthotropic Parameter Identification Using Biaxial Tensile Tests on Cruciform Specimens [J]. International Journal of Solids and Structures, 44(5) (2007) 1643-1656.

[24] M. Merklein, M. Biasutti. Development of a Biaxial Tensile Machine for Characterization of Sheet Metals [J]. Journal of Materials Processing Technology, 213(6) (2013) 939-946.

[25] F. Abu-Farha, L. G. Hector Jr, M. Khraisheh. Cruciform-shaped Specimens for Elevated Temperature Biaxial Testing of Lightweight Materials [J]. JOM, 61(8) (2009) 48-56.

[26] José Calaf Chica, Pedro Miguel Bravo Díez, MónicaPreciadoCalzada. Improved Correlation for Elastic Modulus Prediction of Metallic Materials in the Small Punch Test [J]. International Journal of Mechanical Sciences, 134 (2017) 112-122.

[27] Jose Calaf Chica, Pedro Miguel Bravo Díez, Mónica Preciado Calzada. Development of an Improved Prediction Method for the Yield Strength of Steel Alloys in the Small Punch Test [J]. Materials \& Design, 148 (2018) 153-166.

[28] E. Priel, B. Mittelman, S. Haroush, A. Turgeman, et al. Estimation of Yield and Ultimate Stress Using the Small Punch Test Method Applied to Non-standard Specimens: A Computational Study Validated by Experiments [J]. International Journal of Mechanical Sciences, 135 (2018) 484-498.

[29] Calaf Chica J , Bravo Díez, Pedro, Preciado Calzada. Optimization of the $\mathrm{t} / 10$ offset correlation method to obtain the yield strength with the small punch test[J]. Journal of Nuclear Materials,2020,534:152-177.

[30]Haroush S , Priel E , Moreno D, et al. Evaluation of the mechanical properties of SS-316L thin foils by small punch testing and finite element analysis[J]. Materials \& design, 2015, 83(oct.15):75-84.

[31] Priel E, Mittelman B, Haroush S, Turgeman A et al. Estimation of yield and ultimate stress using the small punch test method applied to non-standard specimens: A computational study validated by experiments[J]. International Journal of Mechanical Sciences,2018,135:484-498.

[32] García, T.E, Rodríguez C, Belzunce F J , et al. Estimation of the mechanical properties of metallic materials by means of the small punch test[J]. Journal of Alloys \& Compounds, 2014, 582:708-717.

[33] Jose Calaf-Chica, Pedro Miguel Bravo Díez, Mónica Preciado Calzada, et al. A Systematic FEM Analysis of the Influence of Mechanical Properties in the Reliability of the Correlation Methods in the Small Punch Test [J]. International Journal of Mechanical Sciences, 153-154 (2019) 299-309.

[34] D.J. Lloyd, D. Evans, C. Pelow, et al. Bending in Aluminium Alloys AA 6111 and AA 5754 Using the Cantilever Bend Test [J]. Materials Science and Technology, 18(6) (2002) 621-628.

[35] Laurent Mattei, Dominique Daniel, Gilles Guiglionda, et al. Grain Scale Modeling of the Bendability of AA6xxx Al Alloy Sheet [J].Materials Science and Engineering A, 583 (2013) 96-104.

[36] N. Triantafyllidis, A. Needleman, V. Tvergaard. On the Development of Shear Bands in Pure Bending [J]. International Journal of Solids and Structures, 18(2) (1982) 121-138.

[37] Waqas Muhammad, Jidong Kang, Abhijit P. Brahme, et al. Bendability Enhancement of an Age-hardenable Aluminum Alloy: Part I — Relationship Between Microstructure, Plastic Deformation and Fracture [J]. Materials Science and Engineering A, 753 (2019) 179-191.
[38] Peter Groche, Florian Hoppe, Daniel Hesse, et al. Blanking-bending Process Chain with Disturbance Feed-forward and Closed-loop Control [J]. Journal of Manufacturing Processes, 24 (2016) 62-70.

[39] Jyhwen Wang, Suhas Verma, Richard Alexander, et al. Springback Control of Sheet Metal Air Bending Process [J]. Journal of Manufacturing Processes, 10(1) (2008) 21-27.

[40] Kazunari Imai, Junichi Koyama, YingjunJin. High-accuracy V-bending System by Real Time Identifying Material Property [J]. Journal of Materials Processing Technology, 201(1-3) (2008) 193-197.

\section{Biographical notes}

Yong-chuan Duan, born in 1983, is currently a $\mathrm{PhD}$ at Key

Laboratory of Advanced Forming \& Stamping Technology and

Science, Yanshan University, China. He received his $\mathrm{PhD}$ degree from

Yanshan University, China, in 2014. His research interests include

metal material damage and fatigue.

Tel: +86-13253118982; E-mail: yonghcuan.duan @ysu.edu.cn

Hai-di Qiao, born in 1994, is currently a master candidate at Key

Laboratory of Advanced Forming \& Stamping Technology and

Science, Yanshan University, China.

E-mail: qiao741380857@163.com

Fang-fang Zhang, born in 1984, is currently a $\mathrm{PhD}$ at Key Laboratory of Advanced Forming \& Stamping Technology and Science, Yanshan University, China. She received her $\mathrm{PhD}$ degree from Yanshan University, China, in 2014. Her research interests include damage and fatigue of braided composites.

Tel: +86-13223387868; E-mail: fangfang.zhang @ysu.edu.cn

Yu Liu, born in 1998, is currently a master candidate at Key

Laboratory of Advanced Forming \& Stamping Technology and

Science,Yanshan University, China.

E-mail: 15538204689@163.com

Le Tian, born in 1993, is currently a master candidate at Key

Laboratory of Advanced Forming \& Stamping Technology and

Science,Yanshan University, China.

E-mail: wolfganglele@gmail.com

Liu Yang, born in 1988, is currently a $\mathrm{PhD}$ at Key Laboratory of Advanced Forming \& Stamping Technology and Science, Yanshan University, China.

E-mail: yangliu@ysu.edu.com

Ying-ping Guan, born in 1963, is currently a professor at Yanshan University, China. He received his $\mathrm{PhD}$ degree from Yanshan Universtiy, China, in 2000. His research interests include metal material damage and fatigue. 
E-mail: gyp@ysu.edu.cn

\section{Appendix}

Appendix and supplement both mean material added at the end of

a book. An appendix gives useful additional information, but even

without it the rest of the book is complete: In the appendix are

detailed charts. A supplement, bound in the book or published

separately, is given for comparison, as an enhancement, to provide

corrections, to present later information, and the like: A yearly

supplement is issue. 
Figures

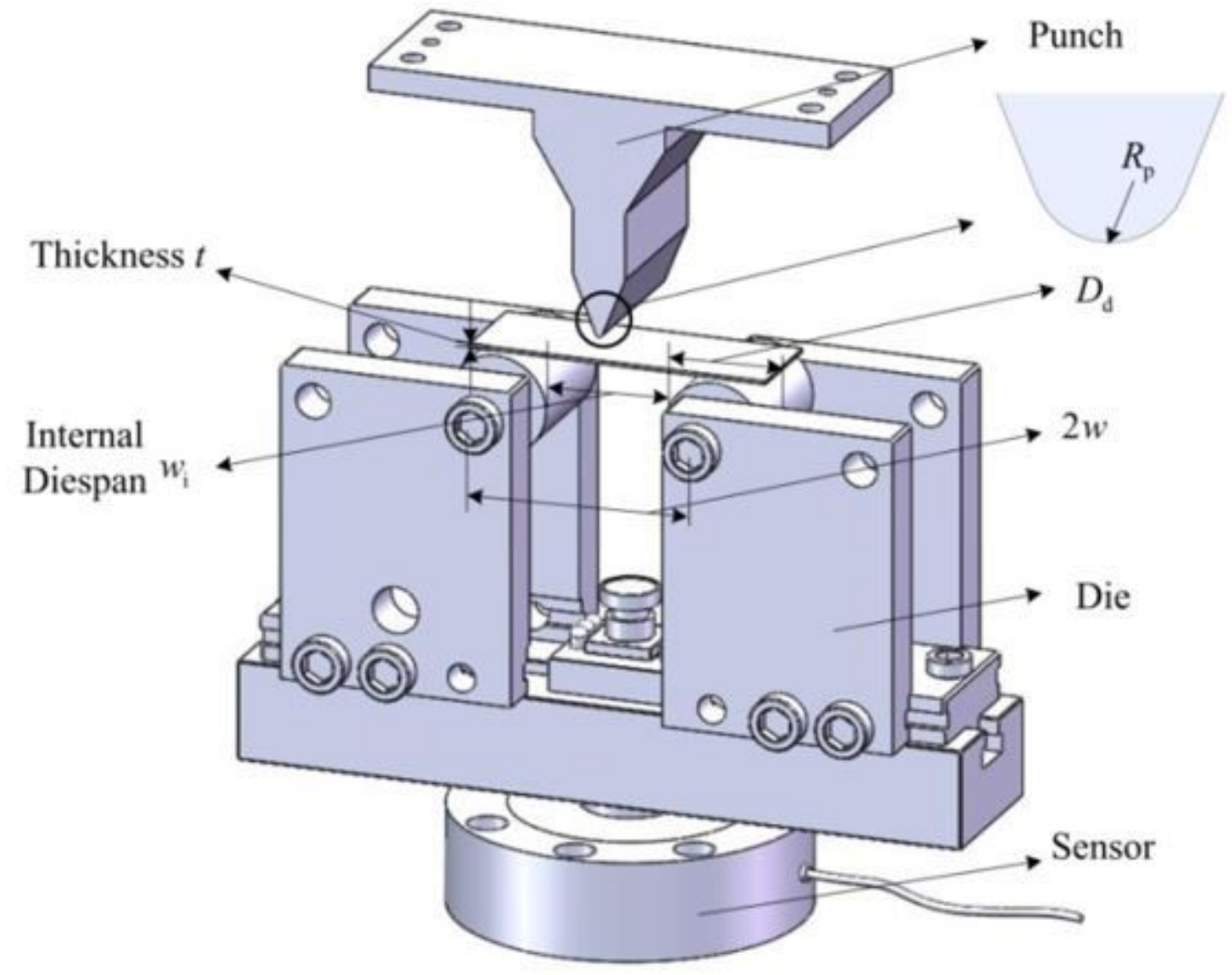

Figure 1

Bending test device. 


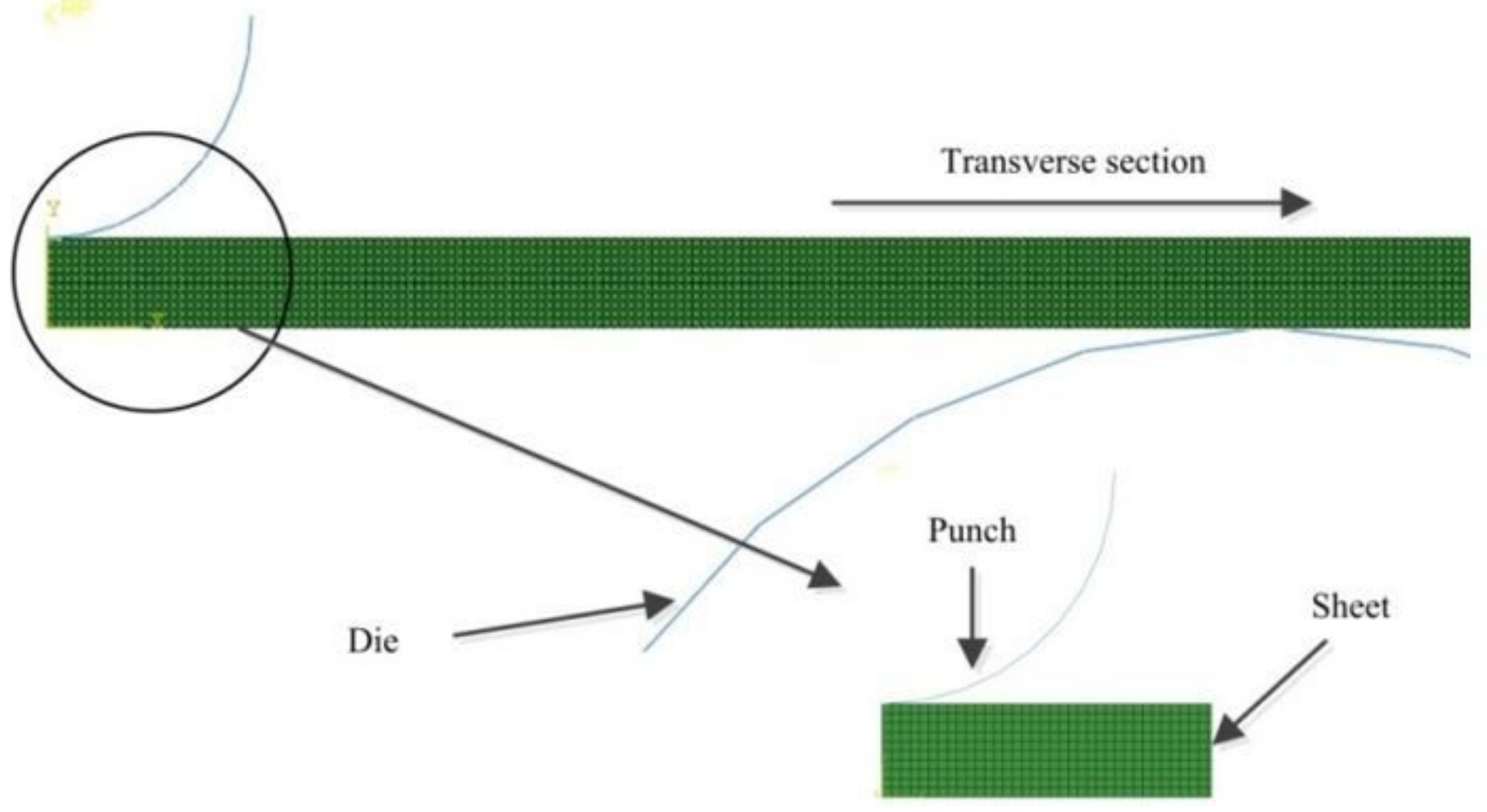

Figure 2

Finite element model of bending test. 

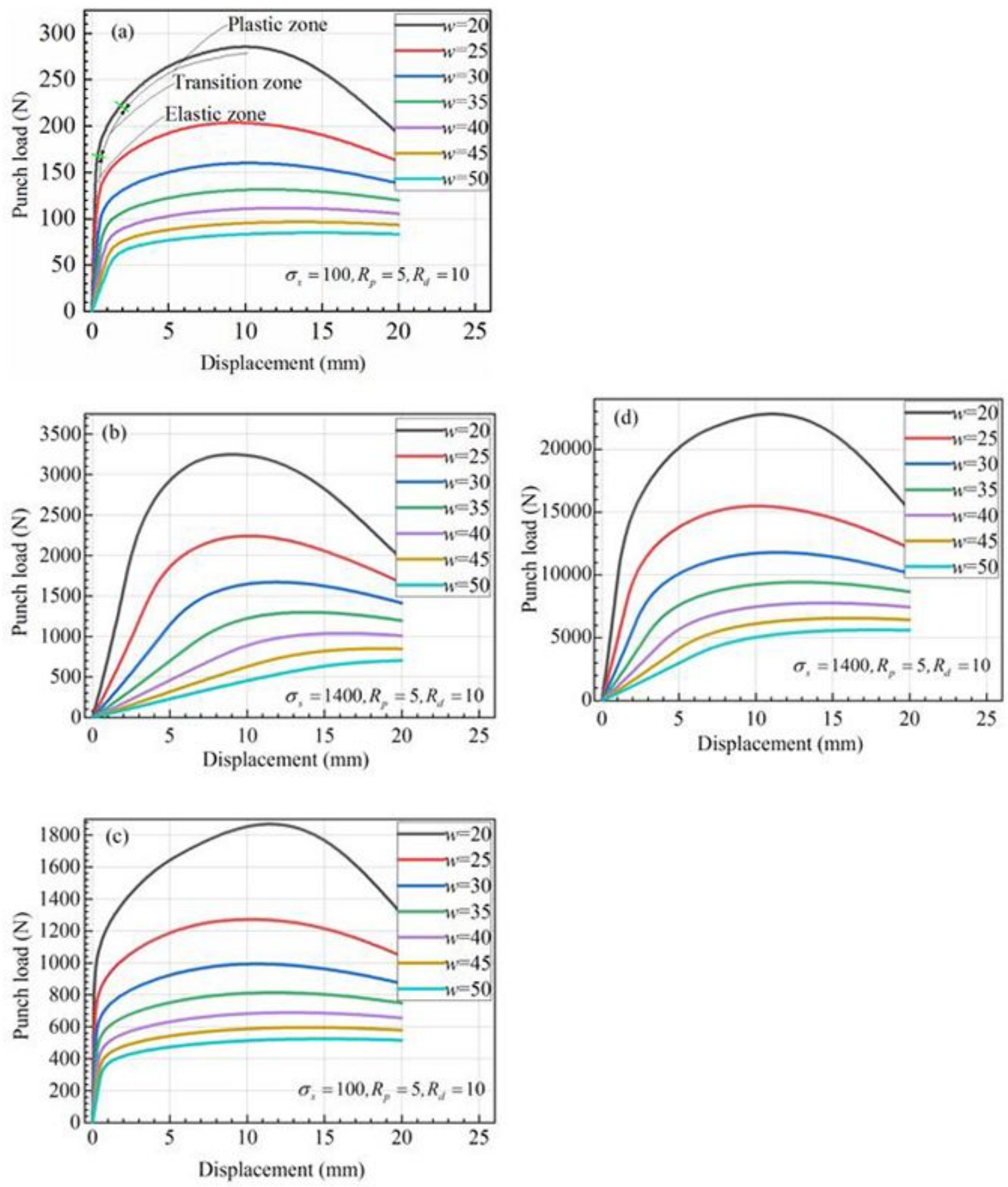

\section{Figure 3}

Curves of bending force travel under different die spans: a) MYL 1mm, b) MYH 1mm, c) MYL 2.35mm, d) MYH 2.35mm 

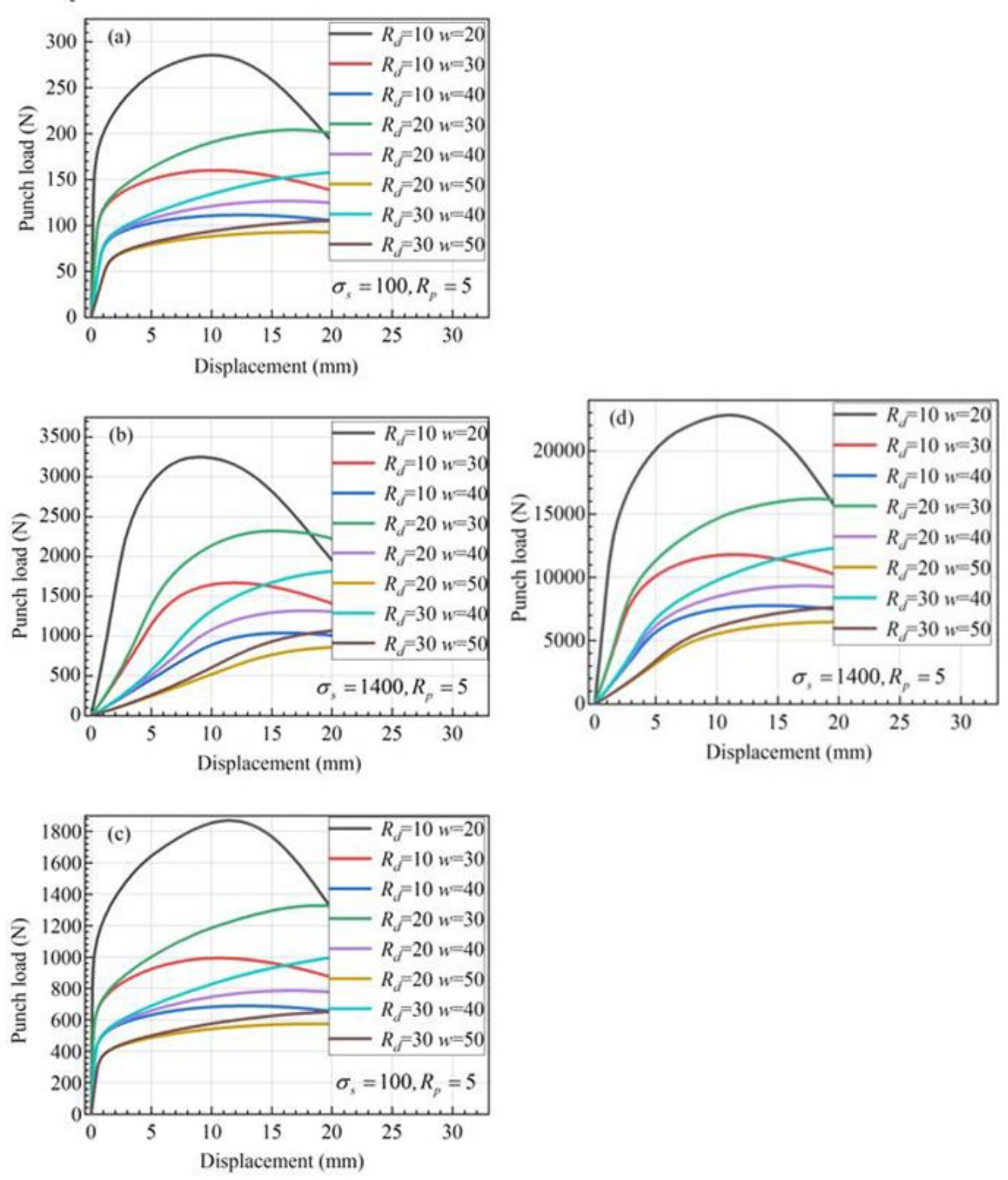

\section{Figure 4}

Curves of bending force travel under different spans and different die radius: a) MYL $1 \mathrm{~mm}, \mathrm{~b}) \mathrm{MYH} 1 \mathrm{~mm}$, c) MYL $2.35 \mathrm{~mm}$, d) MYH $2.35 \mathrm{~mm}$ 

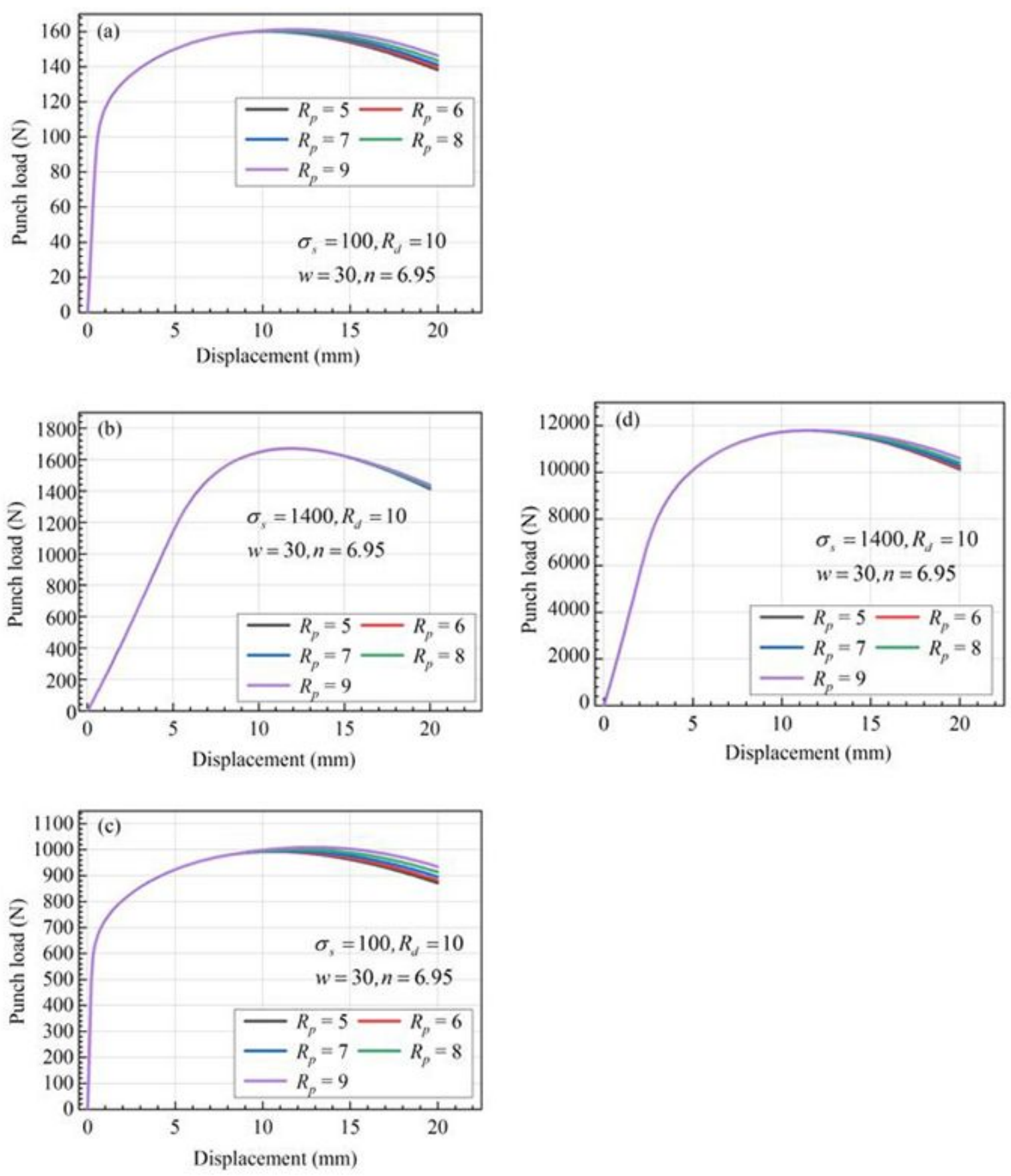

\section{Figure 5}

Curves of bending force stroke under different punch radius: a) MYL 1mm, b) MYH $1 \mathrm{~mm}, \mathrm{c}) \mathrm{MYL}$ $2.35 \mathrm{~mm}, \mathrm{~d}) \mathrm{MYH} 2.35 \mathrm{~mm}$ 


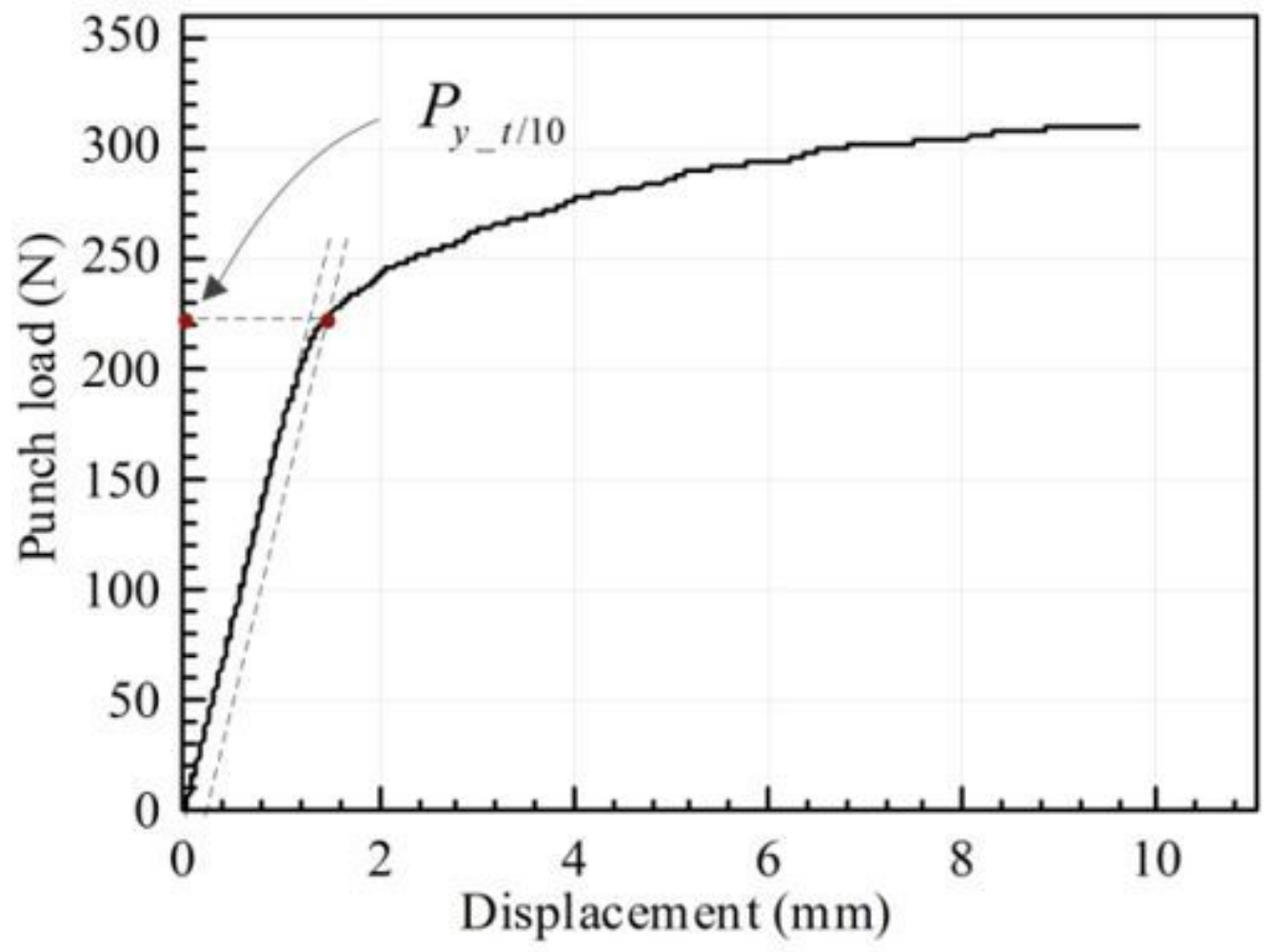

Figure 6

t/10 method to calculate yield load

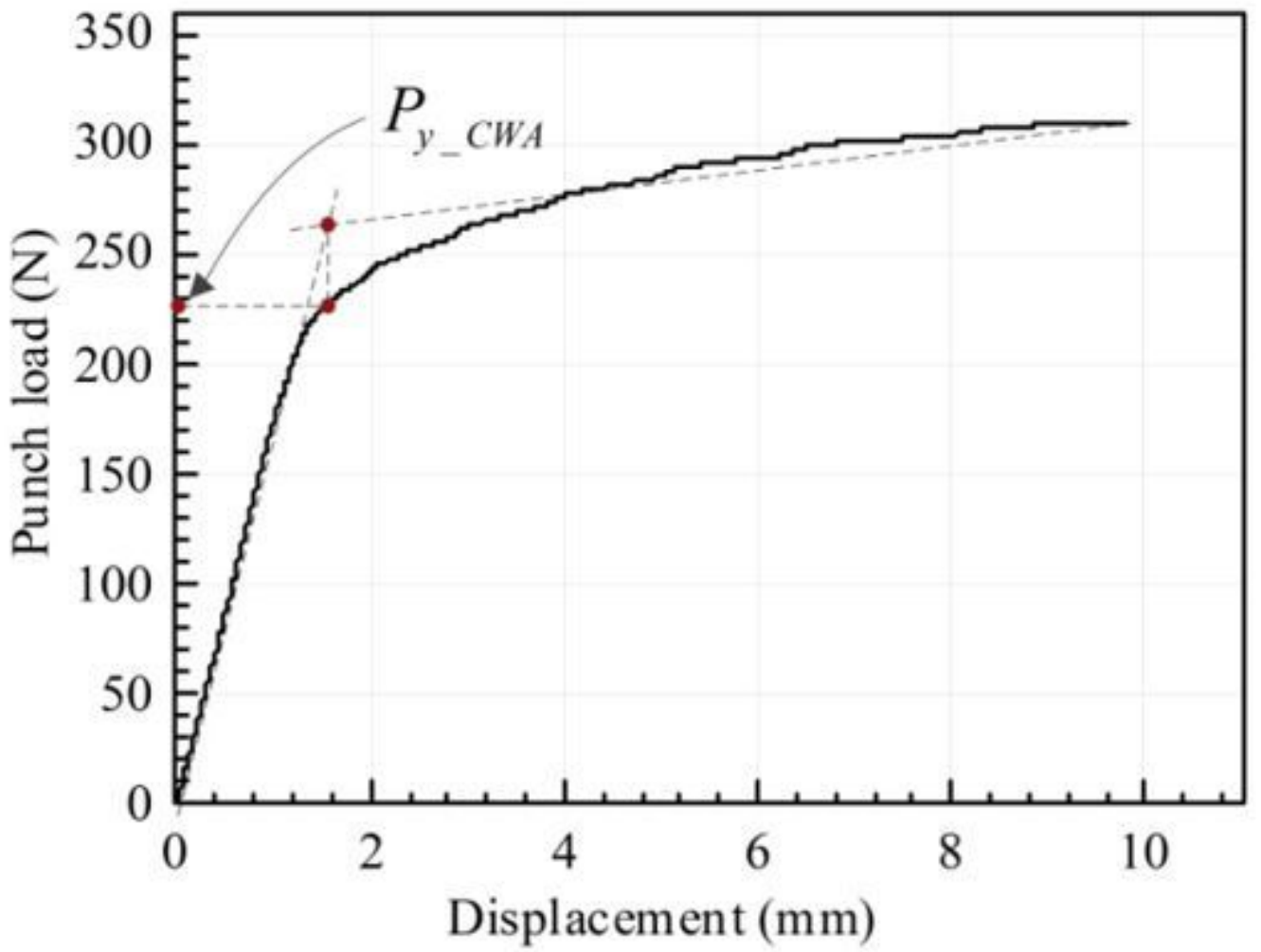

Figure 7 
CWA method to calculate yield load

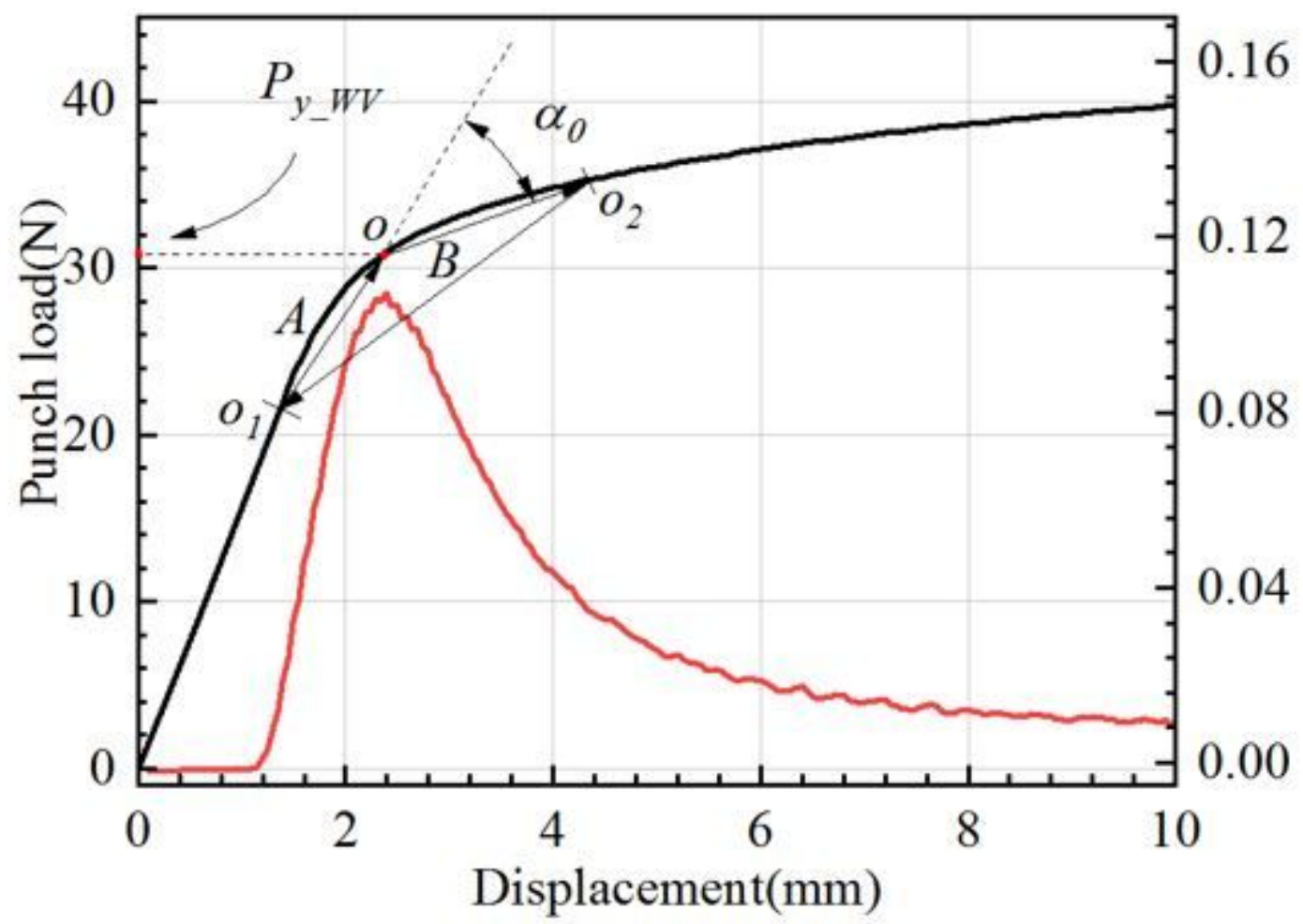

Figure 8

WV method to calculate yield load

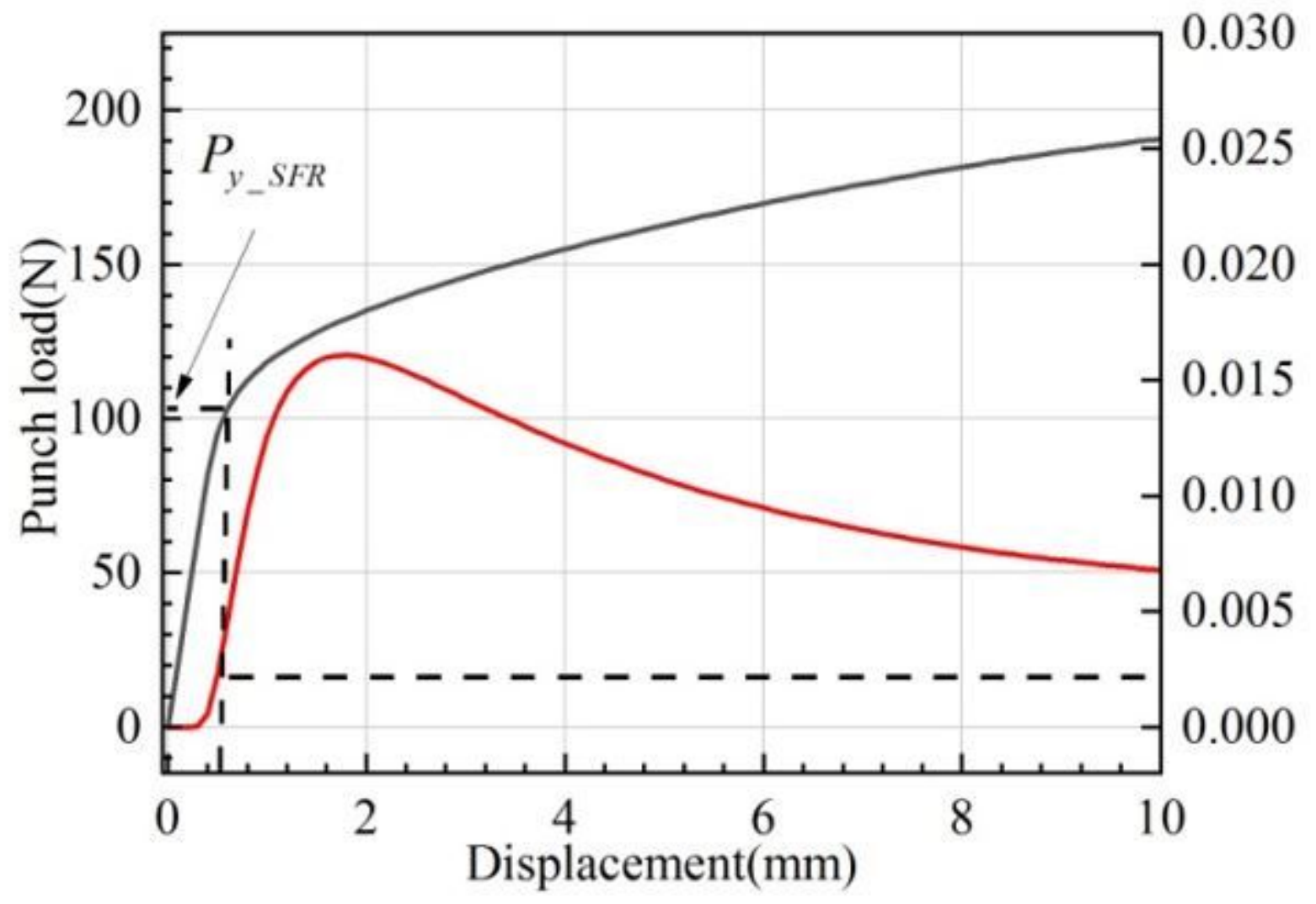

Figure 9 
SFR method to calculate yield load
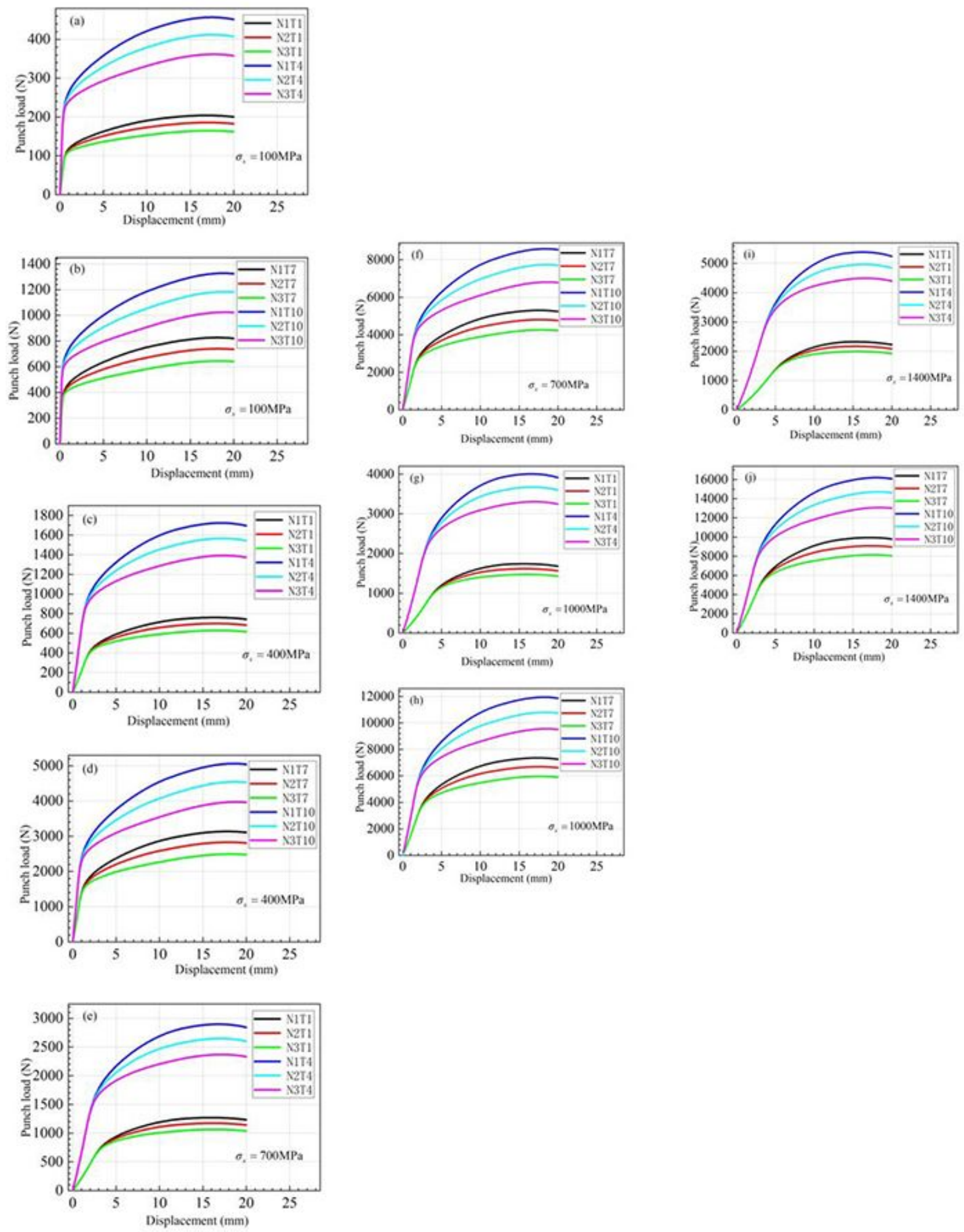

Figure 10

Hypothetical materials' bending force stroke curves 

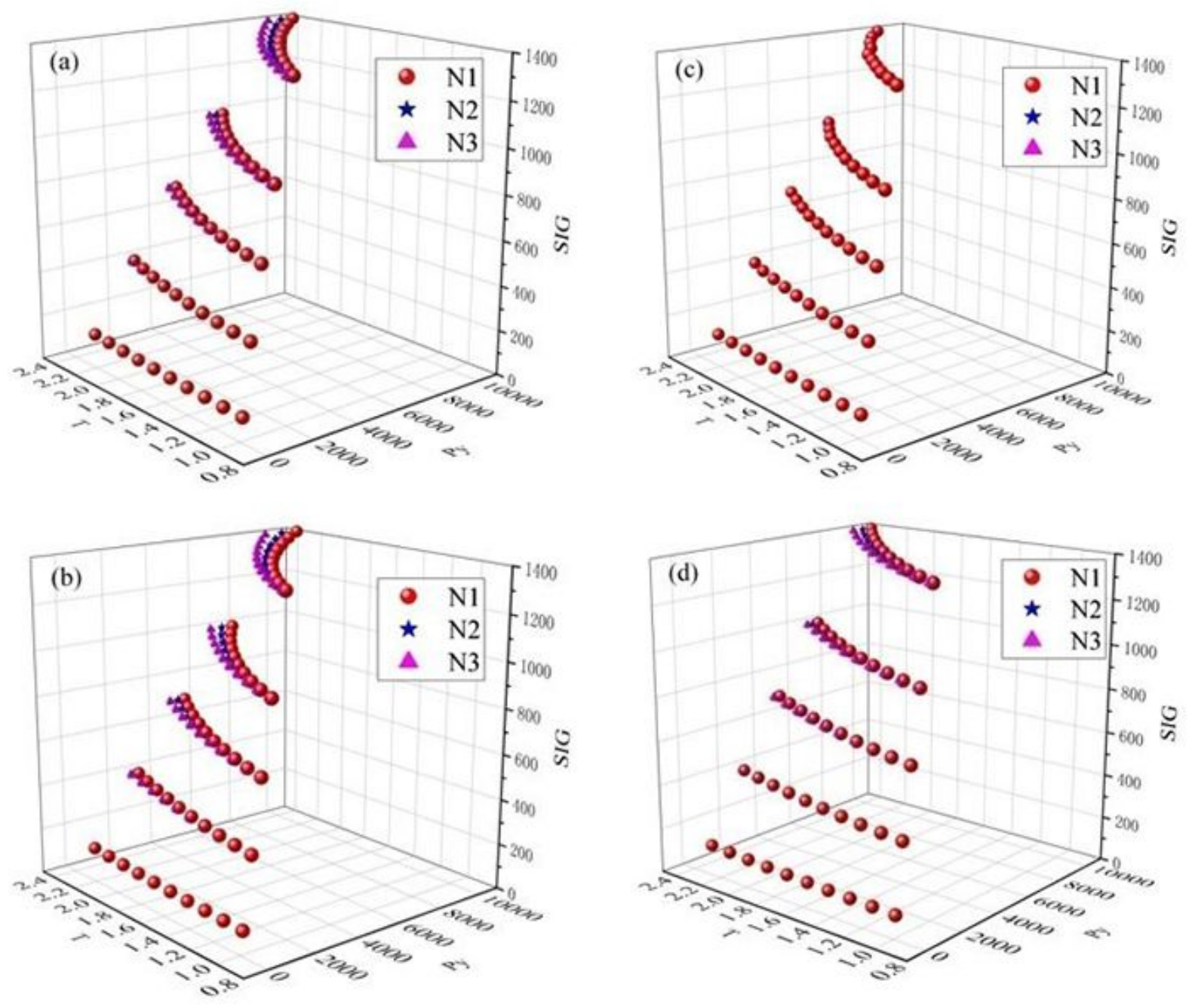

\section{Figure 11}

Yield load identified by different identification methods with different hardening index: a) t/10 method, b) CWA method, c) WV method, d) SFR method 

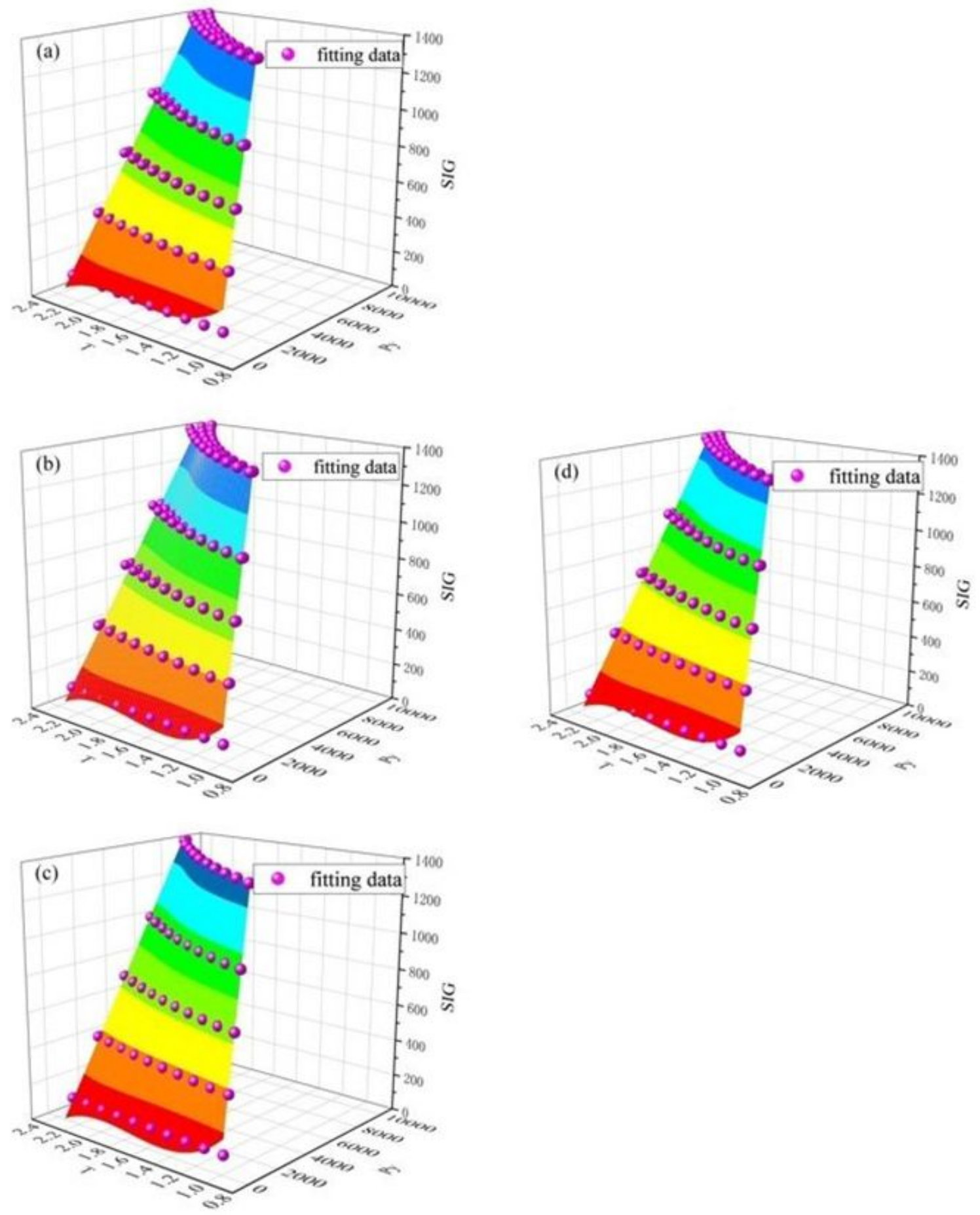

\section{Figure 12}

Fitting results of yield load identified by different identification methods: a) t/10 method, b) CWA method, c) WV method, d) SFR method 

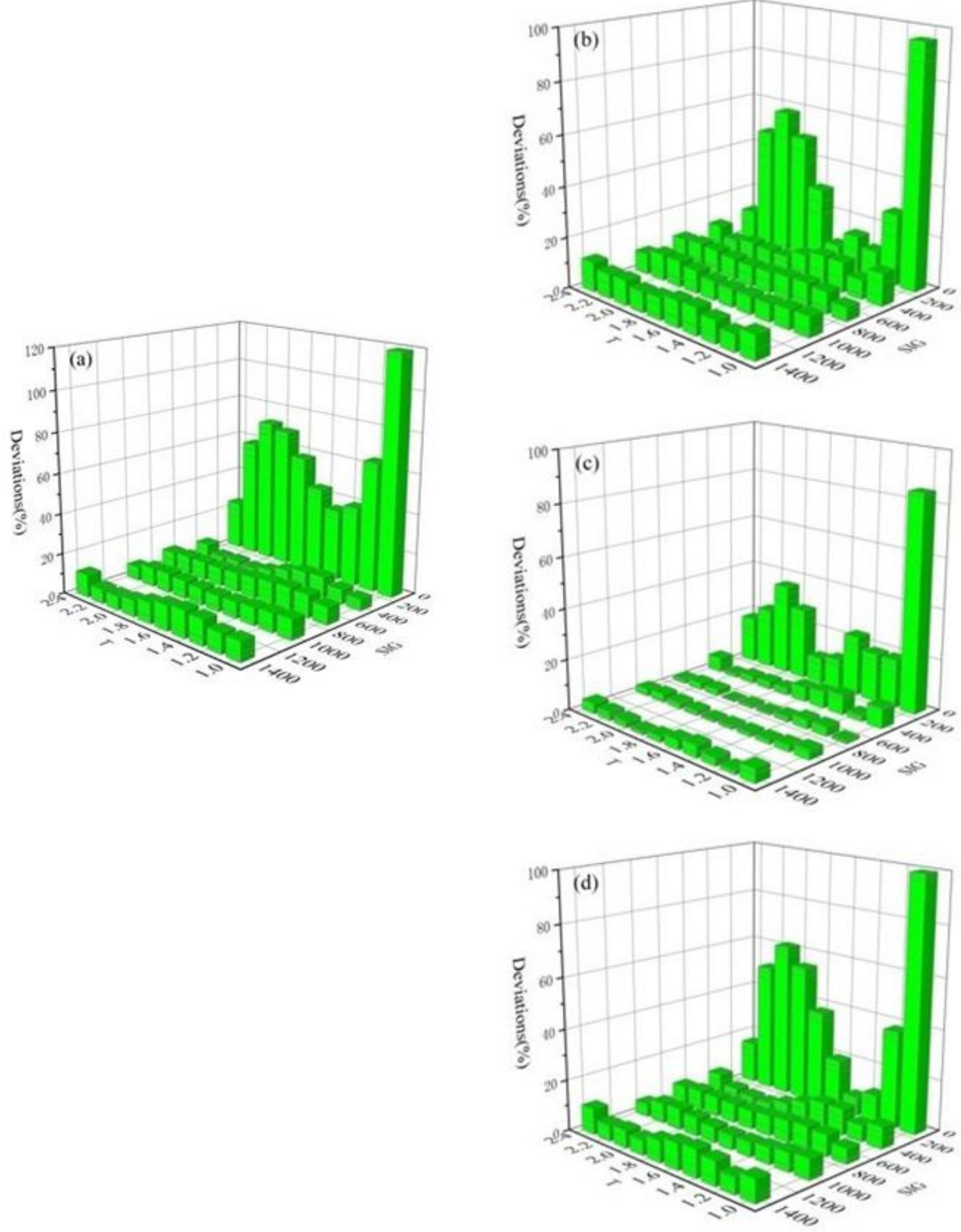

Figure 13

The deviation results of the yield load identified by different identification methods and the fitted surface: a) t/10 method, b) CWA method, c) WV method, d) SFR method 

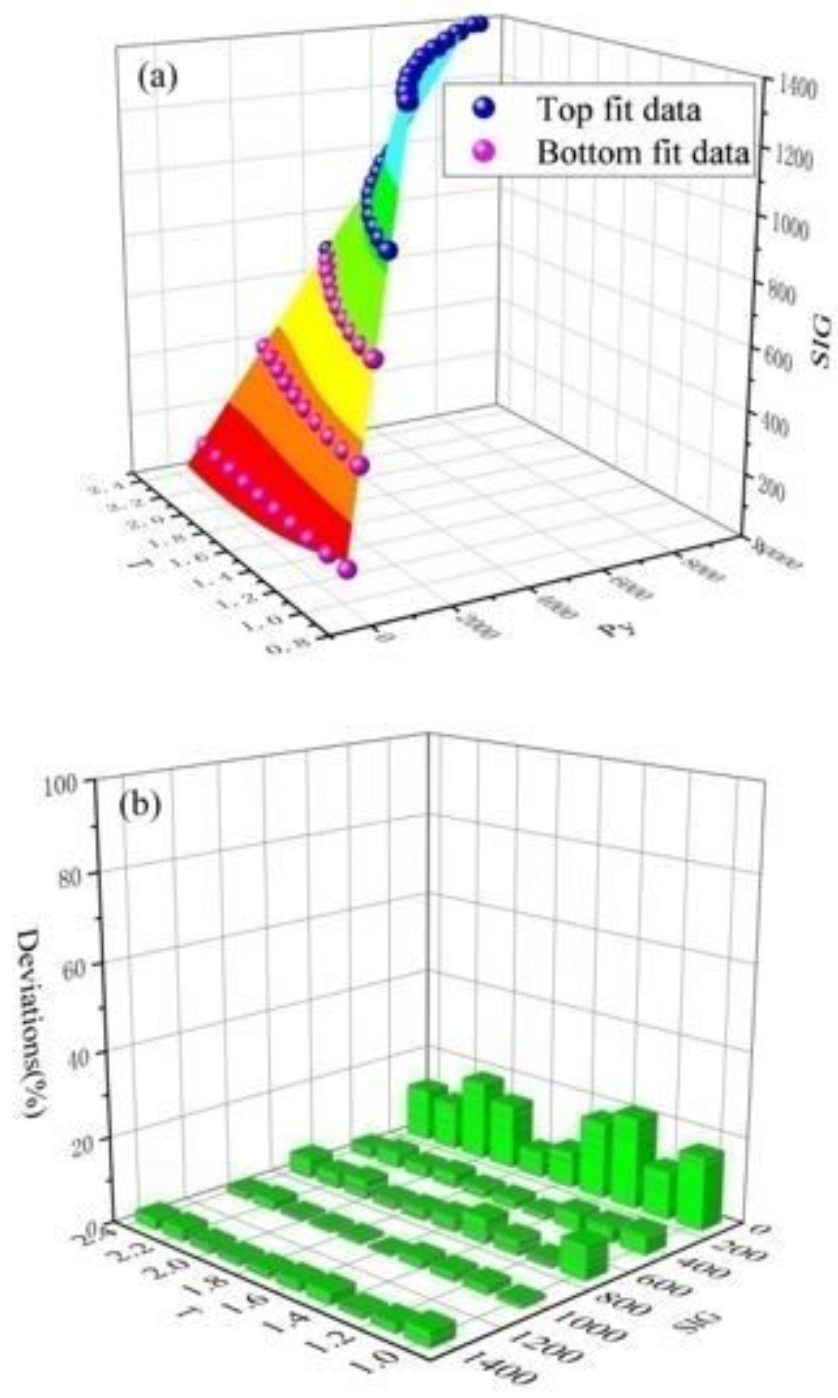

Figure 14

The deviation result between the yield load identified by the WV method and the piecewise fitted surface: a) fitted surface, b) maximum error 


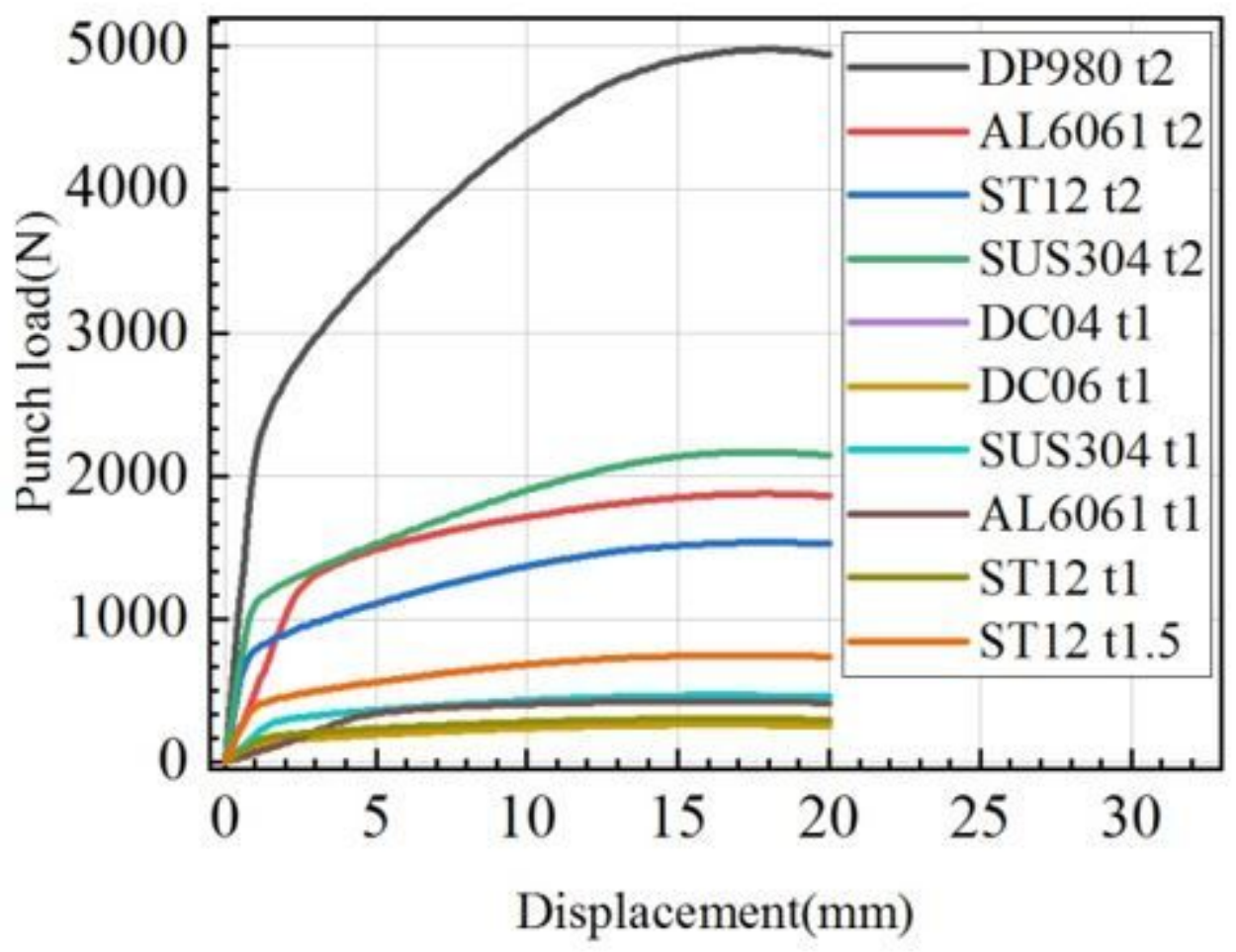

Figure 15

Bending force stroke curves of experimental materials

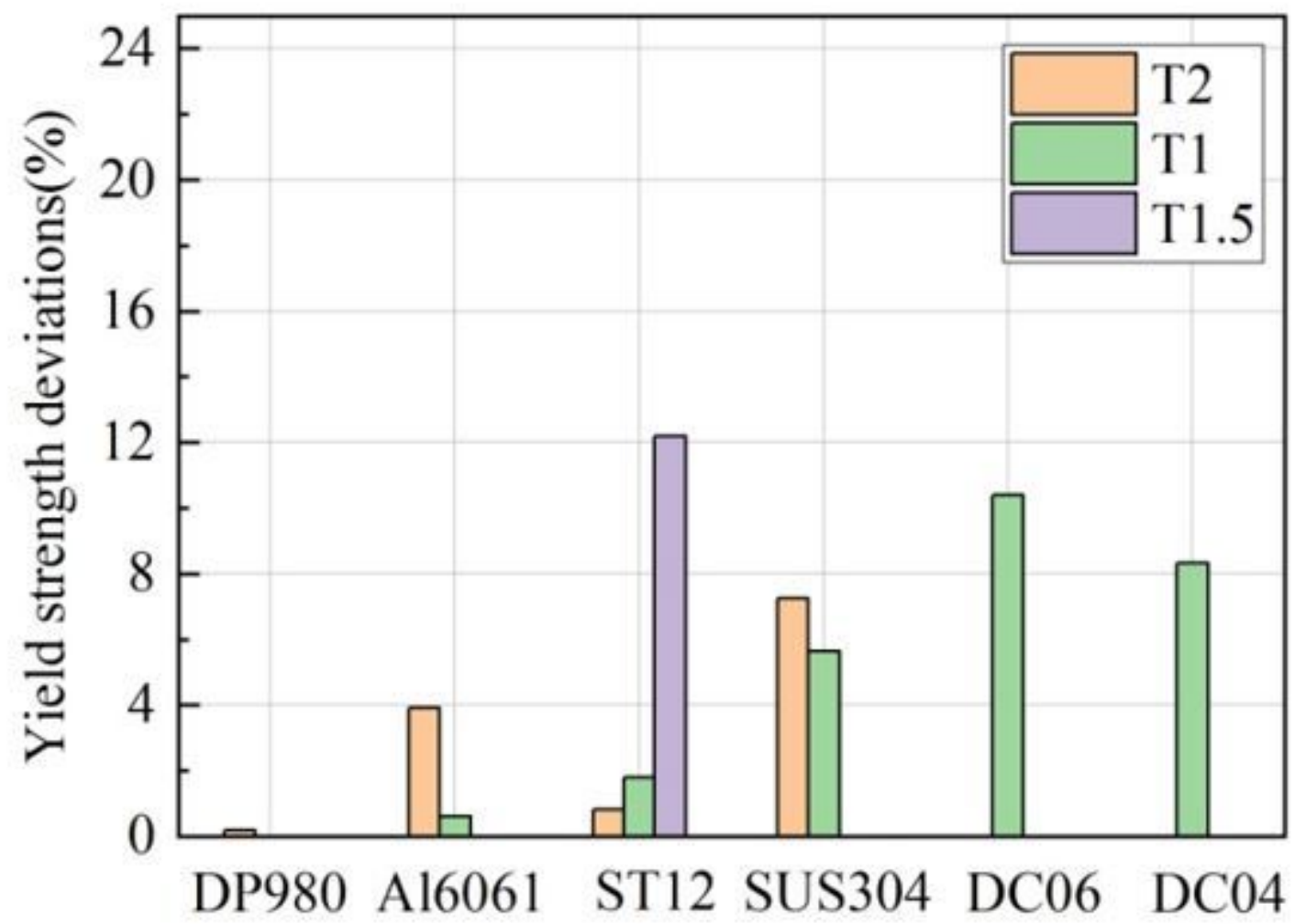

Figure 16 
The deviation results of the yield strengths identified for different materials

\section{Supplementary Files}

This is a list of supplementary files associated with this preprint. Click to download.

- GraphicalAbstract.tif 